Check for updates

Cite this: Mater. Adv., 2020 1,2631

Received 31st August 2020, Accepted 21st September 2020

DOI: 10.1039/d0ma00662a

rsc.li/materials-advances

\title{
Porous carbon materials for microwave absorption
}

\author{
Jin-Bo Cheng, Hai-Gang Shi, Min Cao, Ting Wang, Hai-Bo Zhao (D) * and \\ Yu-Zhong Wang*
}

\begin{abstract}
With the widespread use of microwaves in the civil and military fields, lots of efforts have been made to design high-performance microwave absorption (MA) materials, which should possess thin coating thickness, low density, wide absorption bandwidth, and strong absorption. Recently, porous carbon-based materials combined with the advantages of carbon and porous microstructures have demonstrated great advances in microwave absorption, due to their ultralow density, high specific surface area, strong dielectric loss, and excellent corrosion resistance. In this review, we summarize the recent progress in porous carbonbased MA materials encompassing composition and microstructure design. Representative fabrication methods, structure characterization, and properties of materials are highlighted in detail. The corresponding electromagnetic energy attenuation mechanisms, especially the effects of porous microstructures, are discussed as well. Moreover, the relative shortcomings, ongoing challenges, and perspectives at this frontier are presented.
\end{abstract}

\section{Introduction}

Recently, with the rapid development and expanding applications of electric technologies, electromagnetic (EM) waves have brought great convenience to people's lives. ${ }^{1}$ However, excess EM waves lead to some problems due to their harmful effects. For example, EM waves emitted by mobile phones would affect the normal work of precision electronic medical devices; EM waves can also seriously interfere with aircraft communications; besides, EM waves cause long-term harm to human body health; and, in the military aspect, the development of radar detection technology based on EM waves seriously threatens the survivability of aircraft, tanks, and ships. ${ }^{2-4}$ Therefore, developing advanced microwave absorption (MA) materials to eliminate unwanted EM energy has attracted great interest at the global scale..$^{5-9}$ Usually, ideal MA materials should be thin in thickness, light in weight, wide in bandwidth, and strong in absorption. Furthermore, to increase the service life of MA materials, they need to display excellent environmental corrosion resistance (such as high temperature and humidity resistance, and thermal oxidization stability). ${ }^{2,10-12}$ Consequently, the light weight, large surface areas, excellent environmental stability, and strong EM wave

Collaborative Innovation Center for Eco-Friendly and Fire-Safety Polymeric Materials (MoE), State Key Laboratory of Polymer Materials Engineering, National Engineering Laboratory for Eco-Friendly Polymer Materials (Sichuan), College of Chemistry, Sichuan University, Chengdu, 610064, China. E-mail: yzwang@scu.edu.cn, haibor7@163.com; Fax: +86-28-85410259; Tel: +86-28-85410755 attenuation abilities of carbon-based materials make them very promising in microwave absorption.

Compared with traditional absorbing materials $\left(\mathrm{Fe}_{3} \mathrm{O}_{4}, \mathrm{SiC}\right.$, $\mathrm{BaTiO}_{3}$, magnetic metal powders, etc.), carbon-based materials exhibit lower densities and stronger EM wave absorption abilities. ${ }^{12-20}$ For example, there have been lots of studies on graphene and carbon nanotubes (CNTs) applied in MA fields due to their strong electrical conductivities, low percolation thresholds, and organized nanostructures. ${ }^{6,11,14,21-46}$ However, the costeffective and large-scale production of graphene and CNTs remains a crucial challenge for commercial application, which seriously hinders their applications. Recently, porous carbon (PC) materials combined with carbon and porous features can be produced by a facile and simple synthesis method with low-cost raw materials, which has aroused renewed interest.

PC materials have been widely studied and applied in many fields such as catalysis, batteries, and supercapacitors due to their high specific areas, tunable pore sizes and pore structures. ${ }^{47-56}$ Meanwhile, these advantages also make PC materials expected to become MA materials: firstly, a porous material could be regarded as a composite composed of the solid component and air component, which efficiently decreases the density and increases the impedance matching. ${ }^{57}$ Secondly, the porous structure could generate more interface polarization loss, which would increase absorption of EM wave energy.$^{58}$ Moreover, by utilizing different templates (aerogels, foams, metal-organic frameworks (MOFs), and biomass), PC could be prepared with controllable characteristics, i.e. pore size, pore structure, and graphitization of carbon, which directly influence the MA performance. ${ }^{59-64}$ 
However, pure PC materials always have the problems of a single dielectric loss mechanism and impedance mismatching. As a result, tremendous efforts have been made to exploit PC-based MA materials, containing optimized pore sizes and pore structures, adjusting the graphitization of carbon, and introducing diversified components. Therefore, it is necessary and meaningful to summarize the research progress of PC-based absorbers in recent years.

In this review, we first discuss and conclude the factors that influence the MA properties of PC-based materials. Then, according to the components and fabrication template, the research progress of various PC-based absorbing materials is comprehensively summarized. Finally, we put forward some challenges and development perspectives for future microwave absorbing materials.

\section{Contribution of porous structures to microwave absorption}

It is well known that porous structures can effectively reduce the densities of absorbers, which meets the lightweight requirement for absorbing materials. More importantly, recent studies have confirmed that porous structures of materials can play a positive role in microwave absorption. The main contribution factors of porous structures to MA have been summarized as follows. Firstly, porous structures can enhance the attenuation ability of electromagnetic waves by providing multiple paths for the incident EM waves and greatly increasing the contact probability between EM waves and the absorber. Thus, the EM waves can be absorbed or scattered many times in the pore channel, and further dissipated into heat, resulting in a strong attenuation property. ${ }^{65}$

Secondly, porous structures can improve the impedance matching of materials for EM waves. Porous materials could be regarded as a composite composed of the solid component and air component, where Maxwell Garnett (MG) theory is a symbolic mechanism for exploring the variation of the effective permittivity. ${ }^{57,66,67}$ MG theory can be expressed as:

$$
\varepsilon_{\mathrm{eff}}^{\mathrm{MG}}=\varepsilon_{1} \frac{\left(\varepsilon_{2}+2 \varepsilon_{1}\right)+2 p\left(\varepsilon_{2}-\varepsilon_{1}\right)}{\left(\varepsilon_{2}+2 \varepsilon_{1}\right)-p\left(\varepsilon_{2}-\varepsilon_{1}\right)}
$$

where $\varepsilon_{1}$ represents the permittivity of the solid, $\varepsilon_{2}$ is the permittivity of air, and $p$ means the volume fraction of air. Based on the formula, an increase in the pore volume would reduce the effective permittivity, which would contribute to better connectivity with free space, and EM waves will enter the absorber more easily. Consequently, porous structures would increase the impedance matching with free space. Porous structures would also create abundant carbon-air interfaces, where a great quantity of charges would accumulate and increase the interface polarization.

Lastly, the pore size and microstructure also play an important role in MA performance. ${ }^{63,68-70}$ Huang et al. prepared PC with tuneable morphologies. When changing the ratio of tertbutanol to resorcinol, the pore morphologies changed from disordered slit-shaped pores to uniform cage-like pores. Compared to the slit-shaped pores, the uniform cage-like pores in the PC contributed to a longer propagation tunnel and then caused more energy to be dissipated inside the tunnel. ${ }^{64} \mathrm{Xu}$ et al. prepared mesoporous carbon hollow microspheres (PCHMs) with a designable mesoporous shell and interior void (Fig. 1a). The PCHMs exhibited a minimum reflection loss (RL) of $-84 \mathrm{~dB}$, almost four times as high as that of carbon hollow microspheres without mesopores (CHMs). The large solid-air interface in the mesoporous shell and interior void improved the impedance matching of PCHMs compared with CHMs. In addition, when the microwaves entered the PCHMs, multiple reflection and scattering would occur in the interior void and mesoporous shell. Thus, the ratio of absorption/ reflection would increase since the travel path for microwave attenuation was increased ${ }^{63}$ (Fig. 1b). Cheng et al. designed mesoporous carbon hollow spheres (MCHSs) with different integrated sizes, shell sizes, hollow voids, and mesopores in the shell via a unique simultaneous hydrolyzation-polymerization process. ${ }^{62}$ The shell thickness and integrated sizes were associated with the synergistic effect of hydrolyzation and polymerization reactions, while the hollow voids and mesopores were determined by the $\mathrm{SiO}_{2}$ template morphology. Taking size-controlled MCHSs as an example, the increase in the hollow void sizes led to large $\varepsilon^{\prime}$ and $\varepsilon^{\prime \prime}$ (Fig. 1d). The expanded hollow voids would reduce the density of the MCHSs, thus increasing the filler molar quantity at the same weight, which resulted in a monotonic increase in the complex permittivity. When the filling ratio was $20 \mathrm{wt} \%$, MCHSS-3 presented the best absorption capability due to the compatibility of the impedance matching and attenuation capacity.

\section{Research progress of porous carbon materials for microwave absorption}

\subsection{Pure porous carbon absorbers}

Benefitting from the above-mentioned advantages of porous structure, numerous studies have focused on the design and fabrication of PC-based microwave absorbers. Pure PC absorbers can be produced from biomass, polymer foams or aerogels, and other precursors. Among them, biomass precursors are abundant in nature and usually possess microscale porous structures, and thus a variety of biomass-derived PCs have been used as microwave absorbers. As shown in Fig. 2a, a wide range of biomass (walnut shell, spinach stems, rice husk, waste cotton, shell of pumpkin seeds, loofah sponge, jute, chiffon cake, chicken feathers, fish skin and fir wood) has been utilized to fabricate PCs through direct carbonization processes or activation methods. ${ }^{66,67,71-78}$ The resultant pore structures of the PCs are related to the texture of the biomass, carbonization conditions, or activation conditions.

The direct carbonization process is the simplest method for preparing biomass-derived PCs. After thermal treatment, the $\mathrm{sp}^{3}$ carbons are reduced into graphitized $\mathrm{sp}^{2}$ carbons, and then free electrons can migrate along the $\mathrm{sp}^{2}$ plane and expand the conductivity loss of PCs. The carbonization temperature can adjust the graphitization degree, where the enhancement of the graphitization degree would boost the electrical conductivity $(\sigma)$. 


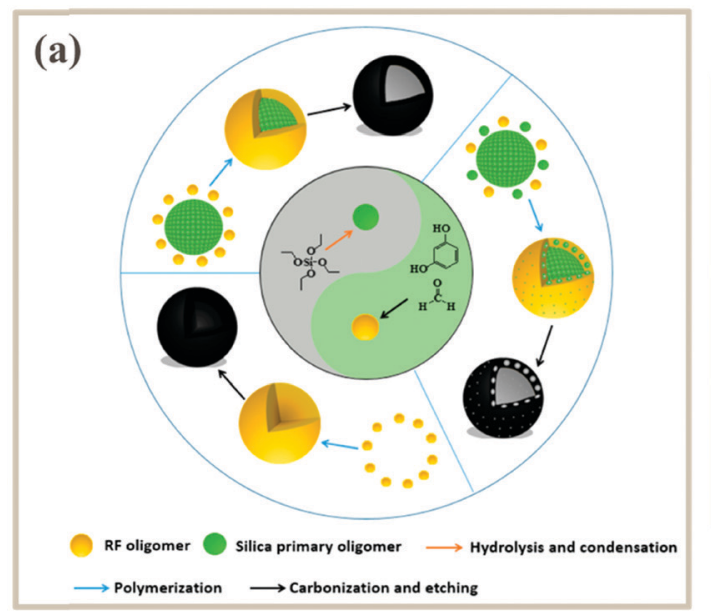

(b)
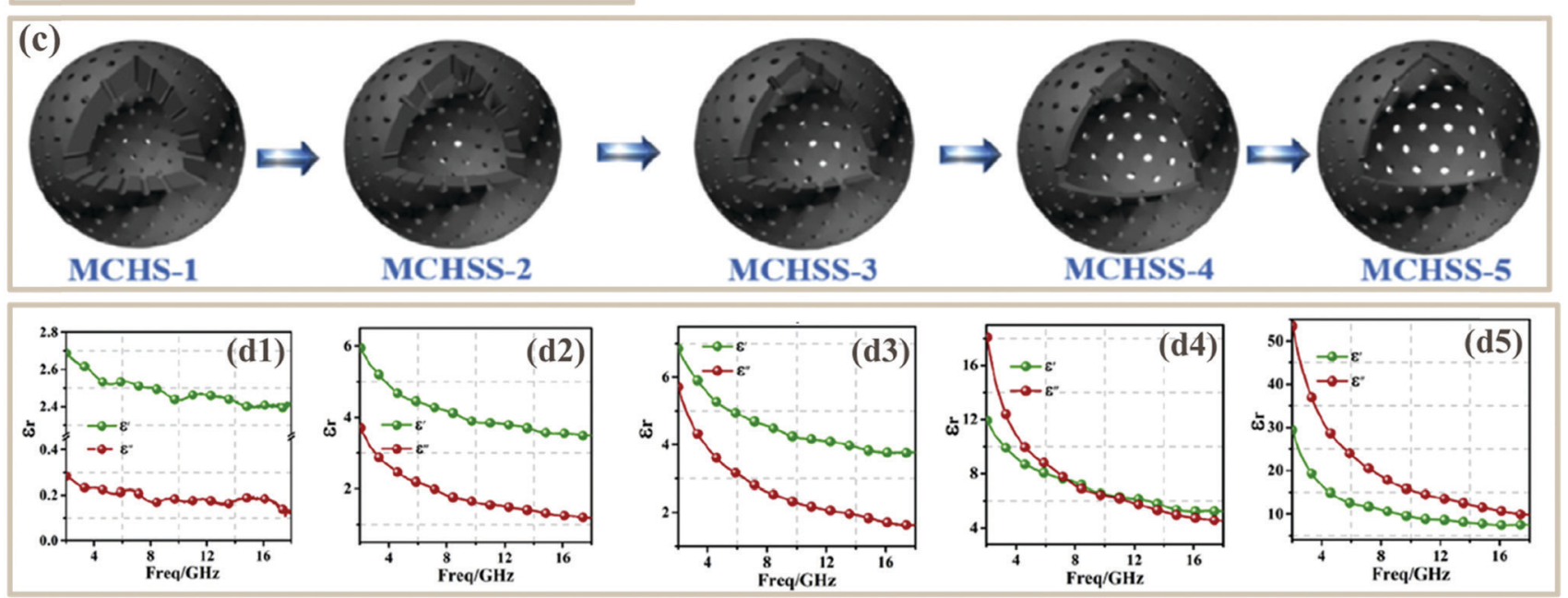

Fig. 1 (a) A schematic illustration of the synthesis of mesoporous carbon hollow microspheres (PCHMs), carbon hollow microspheres (CHMs), and carbon solid microspheres (CSMs), ${ }^{63}$ and (b) schematic illustration of EM wave absorption for PCHMs. ${ }^{63}$ Reproduced with permission from ref. 63 . Copyright (C) 2017, American Chemical Society. (c) Synthesis procedure of different mesoporous carbon hollow spheres (MCHSs): expanded hollow voids and decreased thickness with controlled integrated size. ${ }^{62}$ (d) Complex permittivity variation within 2-18 GHz for MCHS-1 (d1), MCHSS-2 (d2), MCHSS-3 (d3), MCHSS-4 (d4), and MCHSS-5 (d5). ${ }^{62}$ Reproduced with permission from ref. 62. Copyright (C) 2018, Elsevier.

According to eqn (2), the dielectric loss originates from the polarization loss $\left(\varepsilon_{\mathrm{p}}{ }^{\prime \prime}\right)$ and conductivity loss $\left(\varepsilon_{\mathrm{c}}{ }^{\prime \prime}\right),{ }^{79}$

$$
\varepsilon^{\prime \prime}=\frac{\varepsilon_{\mathrm{s}}-\varepsilon_{\infty}}{1+(2 \pi f)^{2} \tau^{2}} 2 \pi f \tau+\frac{\sigma_{\mathrm{ac}}}{2 \pi f \varepsilon_{0}}=\varepsilon_{\mathrm{p}}^{\prime \prime}+\varepsilon_{\mathrm{c}}^{\prime \prime}
$$

where $\varepsilon_{\mathrm{S}}$ is the static permittivity, $\varepsilon_{\infty}$ is the relative dielectric permittivity at the high-frequency limit, $f$ is the frequency, $\tau$ is the polarization relaxation time, $\sigma_{\mathrm{ac}}$ is the alternative conductivity, and $\varepsilon_{0}$ is the dielectric constant in a vacuum $\left(\varepsilon_{0}=8.854 \times\right.$ $\left.10^{-12} \mathrm{~F} \mathrm{~m}^{-1}\right)$. Thus, higher electrical conductivity $\left(\sigma_{\mathrm{c}}\right)$ would improve the dielectric loss. According to theoretical simulations and experimental results, Quan et al. drew the following conclusions: Firstly, the polarization loss played a dominant role in determining the permittivity behaviors in semiconductors due to the limited conductive capability of semiconductor materials. Secondly, the conductivity loss led in determining the permittivity behaviors in graphitized carbon. ${ }^{80}$ Furthermore, the polarization loss can be divided into electronic polarization, ionic polarization, dipolar polarization, and interface polarization. Generally, ionic polarization and electronic polarization occur at relatively high frequency $\left(10^{3}-10^{6} \mathrm{GHz}\right)$, and thus interface polarization and dipolar polarization would be the dominant factors within $2-18 \mathrm{GHz} .{ }^{13}$ Based on Debye relaxation theory, the relationship between $\varepsilon^{\prime}$ and $\varepsilon^{\prime \prime}$ could be used to analyze the polarization relaxation processes, as shown in eqn (3): ${ }^{81,82}$

$$
\left(\varepsilon^{\prime}-\frac{\varepsilon_{\mathrm{s}}+\varepsilon_{\infty}}{2}\right)^{2}+\varepsilon^{\prime \prime 2}=\left(\frac{\varepsilon_{\mathrm{s}}-\varepsilon_{\infty}}{2}\right)^{2}
$$

The plot of $\varepsilon^{\prime}-\varepsilon^{\prime \prime}$ would be semicircles, which is generally regarded as a Cole-Cole semicircle. Every semicircle indicates one Debye relaxation process and the straight-line part is usually related to the conductivity loss. ${ }^{83}$ As for PC-based absorbers, on one hand, the porous structure contributes to the interface polarization. On the other hand, a small number of heteroatoms $(\mathrm{N}, \mathrm{O}, \mathrm{P}, \mathrm{S}$, etc.) maintained in the PC matrix can act as polarization centers under EM fields, leading to dipolar polarization between carbon atoms and doped atoms. Besides, the carbonization process causes some defects to generate dipolar 
(a)

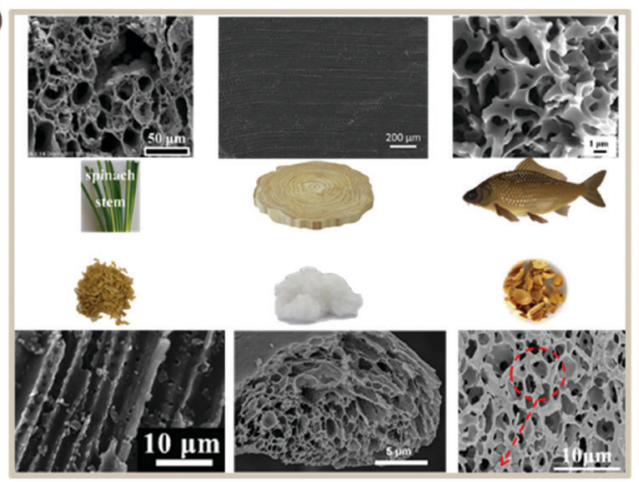

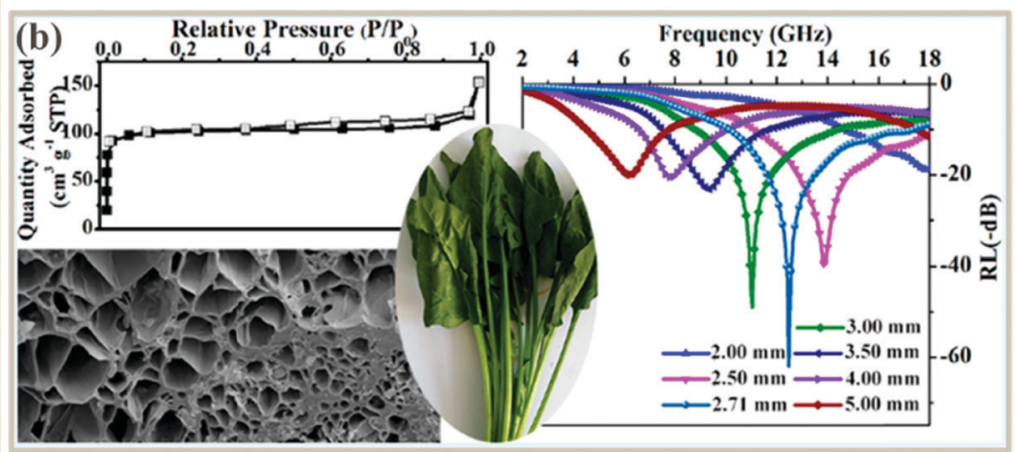

(c)

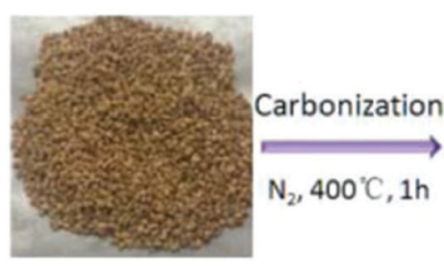

Walnut shell

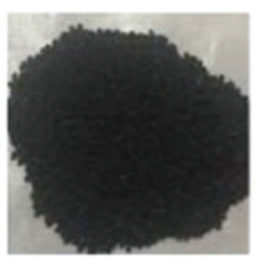

Carbon

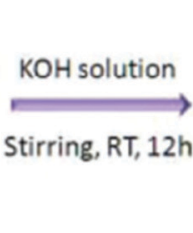

Carbon/KOH

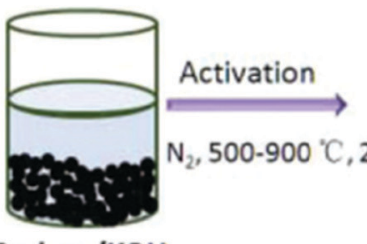

Porous carbon

Fig. 2 (a) Various biomass-derived PCs. Reproduced with permission from ref. 66, 71, 72 and 75-77. Copyright (C) 2019, Elsevier. Copyright (C) 2017, Elsevier. Copyright (C) 2018, Elsevier. Copyright (C) 2018, American Chemical Society. Copyright (C) 2017, Royal Society of Chemistry. Copyright (C) 2019, Springer Nature. (b) $\mathrm{N}_{2}$ adsorption-desorption isotherms, SEM, and RL curves of hierarchical porous carbons (HPCs) from spinach stems. ${ }^{66}$ Reproduced with permission from ref. 66. Copyright (C) 2018, American Chemical Society. (c) Schematic illustration of the fabrication of walnut shell-derived porous carbon. ${ }^{78}$ Reproduced with permission from ref. 78, Copyright (C) 2017, Royal Society of Chemistry.

polarization loss to dissipate the microwave energy. Therefore, biomass-derived PCs possess strong dielectric loss ability from electrical conductivity loss, interface polarization loss and dipolar polarization loss, which was directly influenced by the carbonization conditions, porous microstructures, and hybrid element compositions.

Wu et al. reported hierarchical porous carbons (HPCs) from spinach stems via a one-step carbonization process, where microscale pores were templated by the inherent porous tissues and nanopores were produced by in situ etching by the embedded alkaline metals (Fig. 2b). The specific surface area of the HPC carbonized at $600{ }^{\circ} \mathrm{C}$ reached $345.3 \mathrm{~m}^{2} \mathrm{~g}^{-1}$ and the micro-sized cavities could act as dihedral angles to promote multiple reflection. Besides, the presence of nanosized pores in the HPC could decrease the effective permittivity and optimized the impedance matching. The carbonization temperature can also adjust the chemical composition (graphitization degree) to obtain the optimal microwave absorber. Finally, the spinachderived HPC carbonized at $600{ }^{\circ} \mathrm{C}$ exhibited a strong minimum $\mathrm{RL}$ of $-62.2 \mathrm{~dB}$ and a broad effective absorption bandwidth of $7.3 \mathrm{GHz} .{ }^{66}$ Optimizing the carbonization conditions is vital in determining the MA performance for pure PC materials.

The activation method is used to further increase the surface areas and porosity for PC materials. Usually, biomass is carbonized into a carbon component at relatively low temperatures $\left(<800{ }^{\circ} \mathrm{C}\right)$, and then the resultant carbon is activated at relatively high temperatures. Through activation, porous biomass carbon can produce numerous micropores, and increase solid-void interfaces.
Particularly, the solid-void interfaces can create more interface polarization under EM fields and then generate polarization loss to attenuate microwave energy. Steam, $\mathrm{CO}_{2}, \mathrm{KOH}, \mathrm{K}_{2} \mathrm{CO}_{3}, \mathrm{H}_{3} \mathrm{PO}_{4}$, and $\mathrm{ZnCl}_{2}$ are commonly used as activators during the activation process. Among them, $\mathrm{KOH}$ activation requires relatively low activation temperatures and can generate large specific surface areas. Moreover, $\mathrm{KOH}$ activation is facile and highly efficient, which makes it be widely used. The following chemical reactions may occur at an elevated temperature between carbon and $\mathrm{KOH}$ :

$$
\begin{gathered}
6 \mathrm{KOH}+2 \mathrm{C} \rightarrow 2 \mathrm{~K}+2 \mathrm{~K}_{2} \mathrm{CO}_{3}+3 \mathrm{H}_{2} \\
\mathrm{~K}_{2} \mathrm{CO}_{3}+2 \mathrm{C} \rightarrow 2 \mathrm{~K}+3 \mathrm{CO} \\
\mathrm{K}_{2} \mathrm{O}+\mathrm{C} \rightarrow 2 \mathrm{~K}+\mathrm{CO} \\
\mathrm{K}_{2} \mathrm{CO}_{3} \rightarrow \mathrm{K}_{2} \mathrm{O}+\mathrm{CO}_{2} \\
\mathrm{CO}_{2}+\mathrm{C} \rightarrow 2 \mathrm{CO}
\end{gathered}
$$

After the reaction, $\mathrm{CO}$ and $\mathrm{CO}_{2}$ gases are produced according to reactions (4)-(8), which would generate hierarchical porous carbon. ${ }^{72,84}$ The by-products $\left(\mathrm{K}_{2} \mathrm{O}, \mathrm{K}_{2} \mathrm{CO}_{3}\right.$, etc. $)$ can be easily washed away with acid. Compared to $\mathrm{KOH}$ and $\mathrm{H}_{3} \mathrm{PO}_{4}, \mathrm{ZnCl}_{2}$ is faintly acidic and hardly destroys the nature of the large pores of the biomass. ${ }^{67}$

Qiu et al. used walnut shells to produce porous biomass carbon, where walnut shells were carbonized at $400{ }^{\circ} \mathrm{C}$ followed by $\mathrm{KOH}$ activation at various temperatures (Fig. 2c). The resultant $\mathrm{PC}$ activated at $600{ }^{\circ} \mathrm{C}$ had a specific surface area of $736.2 \mathrm{~m}^{2} \mathrm{~g}^{-1}$, nearly 2 times that of the non-activated sample $\left(435.3 \mathrm{~m}^{2} \mathrm{~g}^{-1}\right)$. 
The author claimed that the PC activated by $\mathrm{KOH}$ possessed a rich porous structure, which would extend the propagation path of incident microwaves to be attenuated (Fig. 2d). Finally, the minimum RL of PC-600 reached $-42.4 \mathrm{~dB}$ with a thickness of $2 \mathrm{~mm}^{78}$

Compared to the direct pyrolysis or activation method, PC absorbers derived from porous foam/aerogel precursors are more common, which can inherit the porous morphology of the template precursors. Zhou et al. fabricated a three-dimensional (3D) carbon foam via hydrothermal and subsequent pyrolysis processes. ${ }^{71}$ The carbon foam (CF) obtained at $650{ }^{\circ} \mathrm{C}$ (CF-650) possessed a large surface area of $1369.3 \mathrm{~m}^{2} \mathrm{~g}^{-1}$ and a hierarchical porous 3D structure, in which the nano-pore size was $0.644 \mathrm{~nm}$ and the micro-pore size was about $1 \mu \mathrm{m}$. The unique architecture endowed CF-650 with a broad bandwidth (RL $<-10 \mathrm{~dB})$ of 8.6 GHz and relatively strong $\mathrm{RL}$ of $-33.5 \mathrm{~dB}$. The $3 \mathrm{D}$ conductive carbon foam network made free electrons easily transport in the presence of EM fields. These electron movements would generate Joule heat to dissipate the microwave energy.

Nanoparticles such as $\mathrm{SiO}_{2}$ are also used as templates to fabricate PC. A series of mesoporous carbon hollow microspheres (MCHSs) with controlled microstructures were achieved, and different types of MCHSs demonstrated different MA properties due to the discrepancy in the volume ratio between the pores and carbon compositions. ${ }^{62}$ Interestingly, Song et al. fabricated highly ordered porous carbon (HOPC) with ordered $\mathrm{SiO}_{2}$ colloidal templates and phenol resin. The unique porous framework allowed HOPC to serve as an effective medium for sufficient electrical loss, and then the composites with 1 and $5 \mathrm{wt} \%$ HOPC showed an EAB of $\sim 2$ and $4.5 \mathrm{GHz}$, respectively. ${ }^{68}$

As mentioned above, we can conclude that regulating the relationship between the microstructure and carbon composition is vital in improving the MA performance for pure PC microwave absorbers. In simple terms, pore structures usually benefit impedance matching while the carbon component contributes to the attenuation ability of microwaves, so the ideal PC absorbers often require compatibility between them. Table 1 summarizes the microwave absorption performances of pure PC-based absorbers reported in recent years. According to Table 1, pure PC-based absorbers usually possess relatively low filler loading $(\leq 30 \mathrm{wt} \%)$ and strong reflection loss (usually $\leq-40 \mathrm{~dB}$ ), which originate from the light weight and strong conductive loss. Nonetheless, the high conductivity of pure PC materials always leads to unfit impedance matching, which makes most microwaves be reflected from the PC surface.
Therefore, introducing other microwave absorbing components into the PC matrix to adjust the MA performance has also attracted much attention.

\subsection{Porous carbon composite absorbers}

According to transmission line theory, the $\mathrm{RL}$ value can be calculated by the following equations:

$$
\begin{gathered}
\mathrm{RL}=20 \log \left|\frac{Z_{\text {in }}-Z_{0}}{Z_{\text {in }}+Z_{0}}\right| \\
Z_{\text {in }}=Z_{0} \sqrt{\frac{\mu_{\mathrm{r}}}{\varepsilon_{\mathrm{r}}}} \tanh \left(\frac{j 2 \Pi f d \sqrt{\varepsilon_{\mathrm{r}} \mu_{\mathrm{r}}}}{c}\right)
\end{gathered}
$$

where $Z_{\text {in }}$ is the input impedance, $Z_{0}$ is the impedance of free space, $\mu_{\mathrm{r}}$ is the complex permeability $\left(\mu_{\mathrm{r}}=\mu^{\prime}-j \mu^{\prime \prime}\right), \varepsilon_{\mathrm{r}}$ is the complex permittivity $\left(\varepsilon_{\mathrm{r}}=\varepsilon^{\prime}-j \varepsilon^{\prime \prime}\right), c$ is the velocity of microwaves in free space, $f$ is the frequency of the microwaves, and $d$ is the thickness of the material. ${ }^{85-88}$ A lower RL means a stronger MA, and $90 \%$ of the microwave energy is absorbed when the RL is lower than $-10 \mathrm{~dB}$. Generally, at a given frequency and coating thickness, tailoring the electromagnetic parameters $\left(\mu_{\mathrm{r}}, \varepsilon_{\mathrm{r}}\right)$ is the main approach to adjust the RL. Based on the loss mechanism, MA materials are usually divided into dielectric materials and magnetic materials. Consequently, constructing MA materials with multiple loss mechanisms is beneficial for enhancing the absorption performance. On the other hand, great MA materials require strong attenuation ability and outstanding impedance matching. The impedance matching can be evaluated by the value of $Z\left(Z=\left|Z_{\text {in }} / Z_{0}\right|\right)$. When $Z$ is equal or close to $1\left(Z_{\text {in }}=Z_{0}\right)$, the microwaves could completely enter the sample and showed no or little reflection on the absorber surface. The attenuation constant $\alpha$ could be calculated according to the following equation: $:^{82,89}$

$$
\alpha=\frac{\sqrt{2} \Pi f}{c} \times \sqrt{\left(\varepsilon^{\prime \prime} \mu^{\prime \prime}-\varepsilon^{\prime} \mu^{\prime}\right)+\sqrt{\left(\varepsilon^{\prime \prime} \mu^{\prime \prime}-\varepsilon^{\prime} \mu^{\prime}\right)^{2}+\left(\mu^{\prime} \varepsilon^{\prime \prime}+\mu^{\prime \prime} \varepsilon^{\prime}\right)^{2}}}
$$

Although pure PC materials possess excellent dielectric loss and strong attenuation ability, their relatively poor impedance matching limits their application in microwave absorption. Hence, introducing more functional components into PC is an effective strategy to expand the MA performance.

3.2.1 Biomass-based PC composite absorbers. Biomass-

\begin{tabular}{|c|c|c|c|c|c|c|}
\hline \multirow[b]{2}{*}{ Sample } & \multicolumn{2}{|c|}{ Minimum RL value } & \multirow[b]{2}{*}{ Loading content (wt\%) } & \multicolumn{2}{|c|}{ Effective absorption bandwidth } & \multirow[b]{2}{*}{ Ref. } \\
\hline & $d(\mathrm{~mm})$ & $\mathrm{RL}_{\min }(\mathrm{dB})$ & & $d(\mathrm{~mm})$ & $f(\mathrm{GHz})$ & \\
\hline PBPC & 4.28 & -68.3 & - & 3.73 & 7.63 & 76 \\
\hline PCHM & 3.9 & -84 & 20 & 1.8 & 2.7 & 63 \\
\hline Walnut shell-derived PC & 2 & -42.4 & 30 & 1.5 & 2.24 & 78 \\
\hline HPC-S & 2.71 & -62.2 & 30 & 2.71 & 7.3 & 66 \\
\hline PC & 2.05 & -50.55 & 10 & 1.85 & 5.32 & 78 \\
\hline $\mathrm{CF}$ & 2.6 & -52.6 & 30 & 3 & 8.6 & 71 \\
\hline
\end{tabular}
based PC obtained from nature resources has aroused great

Table 1 Microwave absorption performances of pure PC-based absorbers in recent literature 
interest due to its environmental friendliness, low cost, and rich source. As mentioned above, the abundant porous structures of biomass could be well preserved after converting into carbon, facilitating microwave absorption. To achieve preferable impedance matching, hybrid element-based compounds (Fe, Co, Ni, $\mathrm{Fe}_{3} \mathrm{C}, \mathrm{Ni}(\mathrm{OH})_{2}, \mathrm{NiO}, \mathrm{MnO}_{2}, \mathrm{Fe}_{3} \mathrm{O}_{4}$, etc. $)$ are introduced into the biomass matrix. ${ }^{75,77,78,90-95}$ Generally, semiconductors ( $\mathrm{ZnO}$, $\mathrm{CuS}, \mathrm{MoS}_{2}$, etc.) often adjust the impedance matching by diminishing the complex permittivity, while magnetic materials (Fe, $\mathrm{Co}, \mathrm{Ni}, \mathrm{Fe}_{3} \mathrm{C}, \mathrm{Fe}_{3} \mathrm{O}_{4}$, etc.) alter the impedance matching via increasing the complex permeability. Moreover, strong interface polarization loss would occur since new absorbing components are introduced. When the decorated compounds are magnetic, magnetic loss is introduced. Typically, magnetic losses are related to natural resonance, eddy current loss and exchange resonance in the microwave frequency range of $2-18 \mathrm{GHz}$ since the hysteresis loss can be neglected in weak fields and domain wall resonance usually occurs at $\mathrm{MHz}$ frequencies. ${ }^{83}$ Besides, if $\mu^{\prime \prime}\left(\mu^{\prime}\right)^{-2} f^{-1}$ keeps constant with the change of frequency, the eddy current loss will be the only magnetic loss. ${ }^{59,96}$

Generally, the method of fabricating biomass-based PC composites could be divided into two types: one is to modify functional compounds on the surface of biomass carbides; another is directly pyrolyzing the biomass containing functional precursor. Wang et al. first acquired porous jute biomass carbon (PJBC) through carbonization and activation processes, and then embellished PJBC with $\mathrm{Fe}_{3} \mathrm{O}_{4}$ nanoparticles via a chemical coprecipitation method at a low temperature of $60{ }^{\circ} \mathrm{C}$ (Fig. 3a). ${ }^{73}$ Based on the different contents of PJBC, the $\mathrm{Fe}_{3} \mathrm{O}_{4} / \mathrm{PJBC}$ samples were labeled as S1, S2, and S3, of which the saturation magnetization $\left(M_{\mathrm{S}}\right)$ was $72.7 \mathrm{emu} \mathrm{g}^{-1}, 65.3 \mathrm{emu} \mathrm{g}^{-1}$, and 29.6 emu g $^{-1}$, respectively (Fig. 3b). For ferromagnetic microwave absorbers, high initial permeability $\left(\mu_{\mathrm{i}}\right)$ usually predicts strong magnetic loss, and high $M_{\mathrm{S}}$ is beneficial to improve the initial permeability $\left(\mu_{\mathrm{i}}\right)$ according to eqn (12):

$$
\mu_{i}=\frac{M_{\mathrm{S}}^{2}}{a k H_{\mathrm{C}} M_{\mathrm{S}}+b \lambda \xi}
$$

where $a$ and $b$ are two constants related to the composition of the microwave absorption materials. In addition, $k$ and $\xi$ are the magnetostriction constant and elastic strain parameter of the crystal, respectively. $M_{\mathrm{S}}$ and $H_{\mathrm{C}}$ are the saturation magnetization and coercivity, respectively. ${ }^{97}$ Thus, $\mathrm{Fe}_{3} \mathrm{O}_{4} / \mathrm{PJBC}$ possessed stronger magnetic loss and better impedance matching than pure PJBC. $\mu^{\prime \prime}\left(\mu^{\prime}\right)^{-2} f^{-1}$ curves were utilized to further analyze the magnetic loss. As shown in Fig. 3c, the values of $\mu^{\prime \prime}\left(\mu^{\prime}\right)^{-2} f^{-1}$ decreased from $2 \mathrm{GHz}$ to $7.5 \mathrm{GHz}$ and then kept almost steady, indicating that natural resonance, eddy current loss, and exchange loss contribute to the magnetic loss. Consequently, the minimum $\mathrm{RL}$ value reached $-39.5 \mathrm{~dB}$ at $6.4 \mathrm{GHz}$ while the effective absorption bandwidth reached $5 \mathrm{GHz}$ at a thickness of $1.6 \mathrm{~mm}$. Yan et al. introduced $\mathrm{Fe}_{3} \mathrm{O}_{4}$ and reduced graphene oxide into a cotton-derived carbon fiber skeleton, and then a maximum absorption of $-63 \mathrm{~dB}$ and a broad absorption bandwidth of $5.8 \mathrm{GHz}$ were achieved. ${ }^{98}$ Generally, directly introducing functional compounds onto the skeleton surface of PC could easily control the adding loading, which is beneficial for the adjustment of the MA performance. However, the pore microstructure of the PC matrix is susceptible to being affected or destroyed during the decoration process.

Besides, many studies also focus on the method of directly pyrolyzing the biomass containing functional precursor. Huang et al. prepared hierarchical porous $\mathrm{C} / \mathrm{Fe}_{3} \mathrm{C}$ composites via drying the gels of gelatin/iron nitrate and subsequent carbonization processes ${ }^{99}$ (Fig. 3d). Micropores (observed from the SEM image) were formed from the self-foaming of the gel while nanopores (observed from the nitrogen adsorption-desorption isotherm) were generated in the carbonization process. Eventually, a minimum RL of $-57.1 \mathrm{~dB}$ and a broad effective absorption bandwidth of $8.16 \mathrm{GHz}$ at a thickness of $2.5 \mathrm{~mm}$ were achieved in the hierarchically porous $\mathrm{C} / \mathrm{Fe}_{3} \mathrm{C}$ composites. Consequently, direct pyrolysis of biomass containing functional precursors can better maintain the pore morphology, while the loading of the functional absorbing component is less controllable.

To sum up, biomass-based PC composite absorbers possess the advantages of low cost (including cheap raw materials and convenient preparation routes), environment friendliness (no toxic solvents) and adjustable MA performance, which give them the prospect of industrial applications in the future. But the irregular pore structures and poor repeatability of biomass remain an urgent problem to be solved. Hence, many researchers designed a matrix with a regular pore structure (metal-organic frameworks, foams, aerogels, etc.) to synthesize regular PC composite absorbers.

3.2.2 MOF-based PC composite absorbers. Metal-organic frameworks (MOF) are composed of metal ions as nodes and organic ligands as linkers. The adjustable components and microstructures, ultrahigh surface areas, and ordered accessible cavities of MOFs make them appropriate for developing PC-based MA materials. ${ }^{59,96,100-116}$ At present, the methods for preparing PC-based absorbers by the calcination of MOFs as a sacrificial template can be divided into three categories: (1) direct pyrolysis of MOFs; (2) the pyrolyzed MOF-based PC was first combined with other materials and then underwent secondary calcination; and (3) the MOF matrix was first compounded with other materials and then calcined to fabricate PC composite absorbers. Generally, the pore structure characteristics of MOF precursors can be transferred into the pyrolyzed products to a large extent, which is one of the significant advantages of MOF-based PC absorbers.

Direct pyrolysis of MOFs is the simplest and fastest method to fabricate MOF-based PC absorbers. After pyrolysis, the organic ligand is pyrolyzed into conductive carbon, while the metal ions can be transferred into a metal or metal oxide. Yin et al. carbonized Co-based zeolitic framework ZIF-67 in a reducing atmosphere $\left(\mathrm{H}_{2} / \mathrm{Ar}\right)$ to fabricate a porous carbon/Co composite ${ }^{107}$ (Fig. 4a). $\mathrm{H}_{2}$ could reduce $\mathrm{Co}^{2+}$ into metallic Co nanoparticles and then catalyzed the growth of CNTs. Controlling the pyrolysis conditions could tune the morphology and microstructure of the composite. Lower temperature led to well-dispersed Co nanoparticles and short CNT clusters, while higher temperatures or longer heating time led to the aggregation of Co nanoparticles. Finally, the porous 


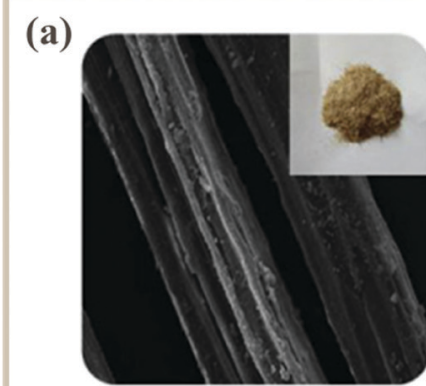

Jute

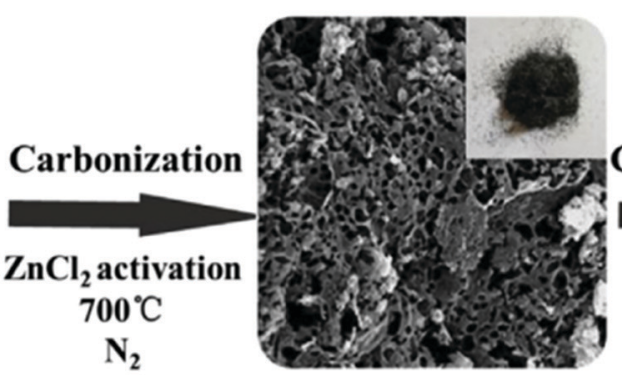

PJBC
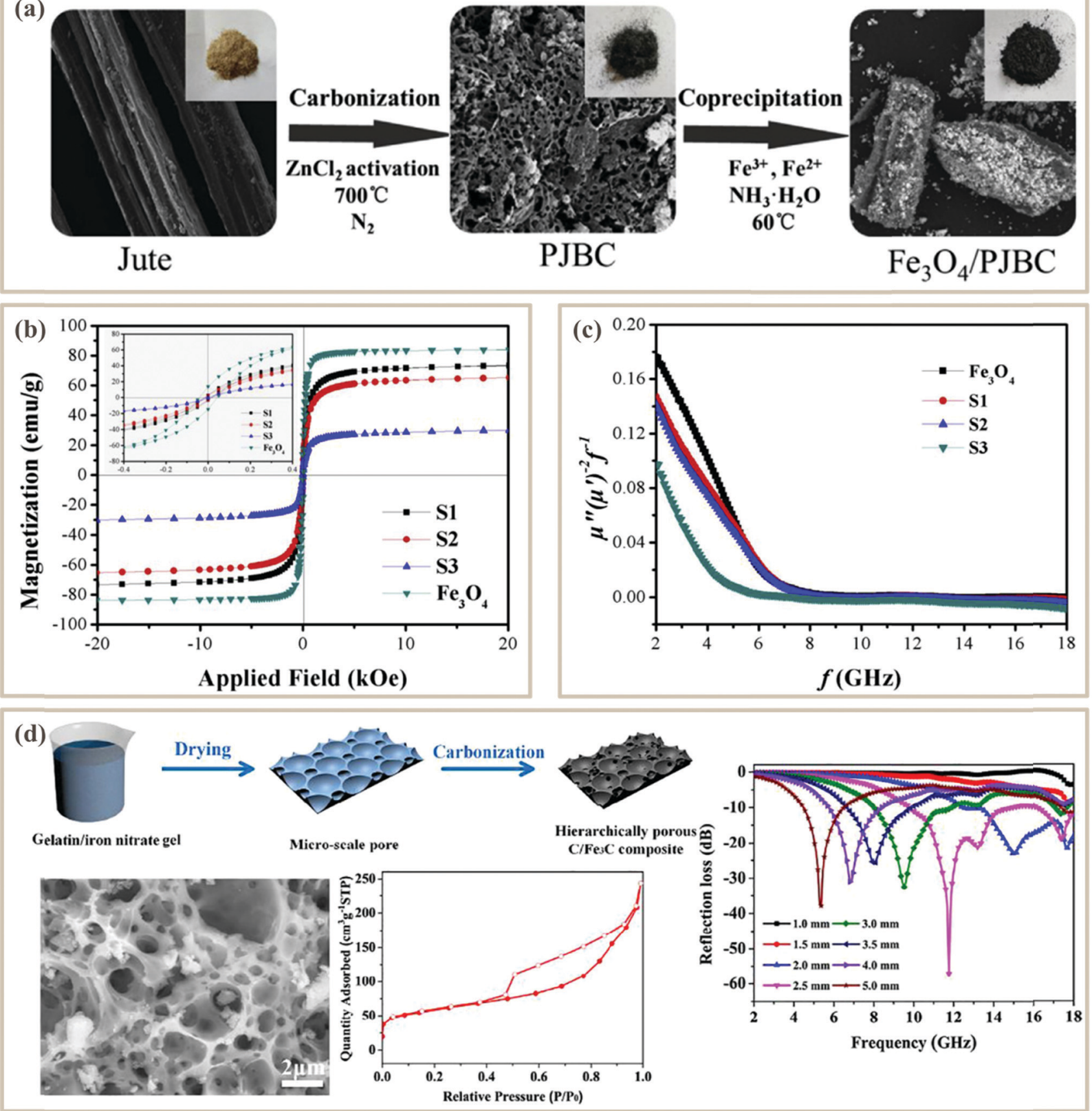

Fig. 3 (a) Schematic illustration of the fabrication of $\mathrm{Fe}_{3} \mathrm{O}_{4} / \mathrm{PJBC}$ composites. ${ }^{73}$ (b) Magnetic hysteresis loops for pure $\mathrm{Fe}_{3} \mathrm{O}_{4}$ and $\mathrm{Fe}_{3} \mathrm{O}_{4} / \mathrm{PJBC}$ composites at room temperature. ${ }^{73}$ (c) Eddy current loss (denoted by $\mu^{\prime \prime}\left(\mu^{\prime}\right)^{-2} f^{-1}$ versus $f$ ) of pure $\mathrm{Fe}_{3} \mathrm{O}_{4}$ and Fe $\mathrm{Fe}_{4} / \mathrm{PJBC}$ composites. ${ }^{73}$ Reproduced with permission from ref. 73, Copyright (C) 2019, Elsevier. (d) Schematic illustration of preparing a hierarchically porous $\mathrm{C} / \mathrm{Fe}_{3} \mathrm{C}$ composite; and the SEM image, nitrogen adsorption-desorption isotherm, and $\mathrm{RL}$ curve of the porous $\mathrm{C} / \mathrm{Fe}_{3} \mathrm{C}$ composite. ${ }^{99}$ Reproduced with permission from ref. 99 , Copyright $\mathbb{C}$ 2018, Elsevier.

CNT/Co composite calcined at $900{ }^{\circ} \mathrm{C}$ for $3.5 \mathrm{~h}$ displayed a strong $\mathrm{RL}$ of $-60.4 \mathrm{~dB}$ at a matching thickness of $1.81 \mathrm{~mm}$. The excellent MA performance originated from the special microstructure and the synergistic effect between conductive CNTs and magnetic Co nanoparticles.

To further tune the impedance matching of PC composites from direct pyrolysis, some researchers tried to mix microwave absorbers with sintered PC composites for a secondary calcination process. Zhang et al. first pyrolyzed ZIF-67 to get Co@nanoporous carbon (Co@NPC), and then coated a $\mathrm{TiO}_{2}$ shell by $n$-butyl titanate hydrolysis and secondary pyrolysis ${ }^{116}$ (Fig. 4b). The obtained Co/NPC@TiO ${ }_{2}$ possessed a high surface area of $232.84 \mathrm{~m}^{2} \mathrm{~g}^{-1}$ and an optimal RL of $-31.7 \mathrm{~dB}$ with an absorbent thickness of $1.5 \mathrm{~mm}$. Ma et al. etched the Co of Co@NPC and then coated 

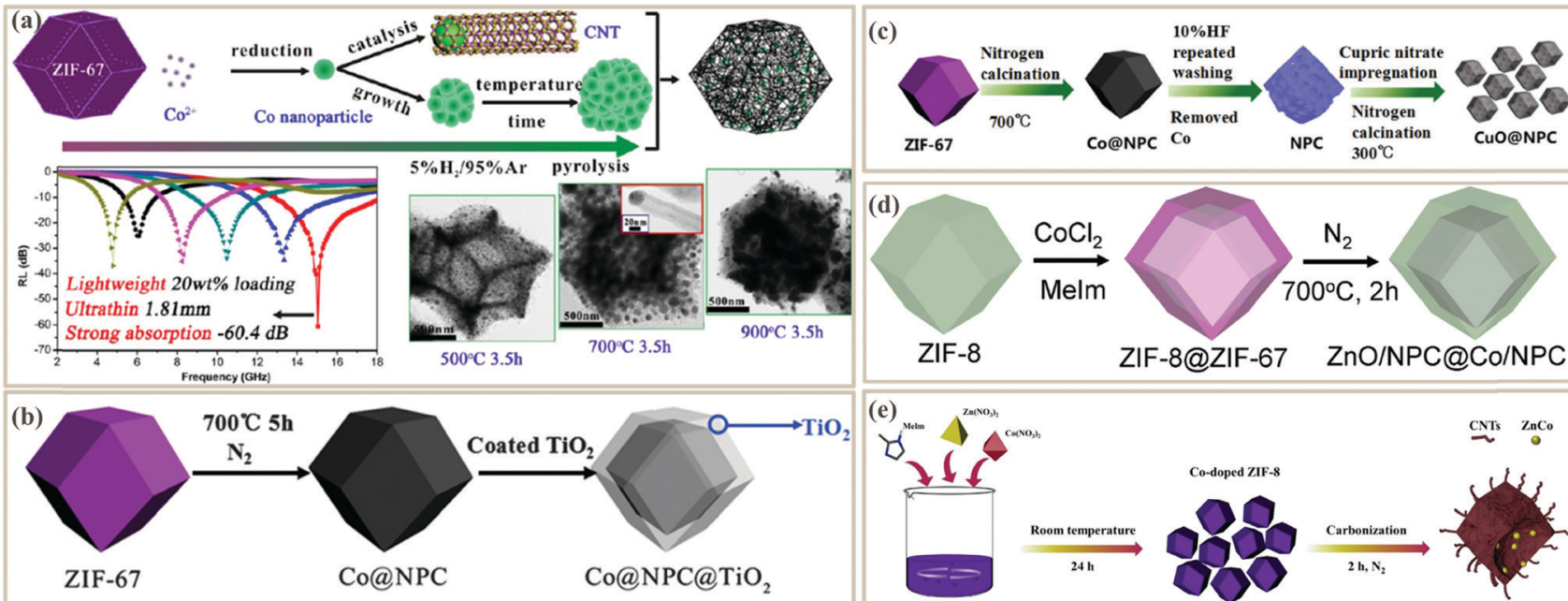

Fig. 4 (a) Synthetic process of a CNT/Co composite from a ZIF-67 precursor, and the RL curve and TEM images of CNT/Co. ${ }^{107}$ Reproduced with

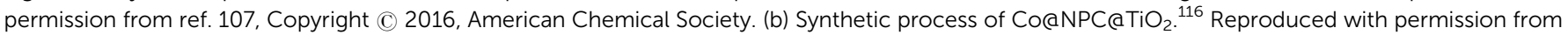
ref. 116, Copyright (C) 2016, Royal Society of Chemistry. (c) Synthetic process of CuO@NPC. ${ }^{109}$ Reproduced with permission from ref. 109, Copyright (C) 2016, Royal Society of Chemistry. (d) Synthetic process of ZnO/NPC aCo/NPC. ${ }^{113}$ Reproduced with permission from ref. 113, Copyright (C) 2016, Royal Society of Chemistry. (e) Synthetic process of Co-doped NPCs/CNTs. ${ }^{111}$ Reproduced with permission from ref. 111, Copyright $\mathbb{C}$ 2019, Elsevier.

CuO nanoparticles at the NPC surface ${ }^{109}$ (Fig. 4c). The hollow $\mathrm{CuO} /$ carbon composite exhibited an optimal $\mathrm{RL}$ of $-57.5 \mathrm{~dB}$ with a thickness of $1.55 \mathrm{~mm}$. The introduction of $\mathrm{TiO}_{2}$ and $\mathrm{CuO}$ could decrease the complex permittivity and improve the impedance matching to get enhanced absorption. However, this method needs a secondary calcination, which increases the cost.

It is necessary to develop a more cost-effective route to reduce the pyrolysis process. One efficient method is by compounding MOFs with different materials to prepare the pyrolysis precursors, while another is introducing other materials during the process of preparing the MOF. Liang et al. grew ZIF-67 on the surface of ZIF-8 via a seed-mediated growth process. After thermal treatment, a core-shell structured ZnO/NPC@Co/NPC composite was obtained ${ }^{113}$ (Fig. 4d). The electromagnetic parameters and the shell thickness could be tuned through varying the mole ratios of $\mathrm{Co}^{2+} / \mathrm{Zn}^{2+}$. The resultant composite can be endowed with multiple loss mechanisms to improve the attenuation ability. Besides, Liu et al. combined a MOF with glucose and fabricated porous $\mathrm{Co} / \mathrm{C}$ composites, and the attenuation ability and impedance matching condition could be improved through the construction of interfacial structures between inner cobalt and surface carbon. Finally, a minimum RL of $-20 \mathrm{~dB}$ could be achieved at a low frequency $(2-8 \mathrm{GHz}) .{ }^{117}$ However, when the compounding conditions are relatively harsh (such as strong acid, strong alkali, and high-temperature environments), the microstructure and the components of the MOF may be destroyed.

Directly introducing different components during MOF preparation is more controllable. Wu et al. synthesized a porous rambutanlike carbon composite using Co-doped zeolitic imidazolate framework-8 (ZIF-8) as a self-sacrificing precursor ${ }^{111}$ (Fig. 4e). The in situ generated Co nanoparticles were uniformly inserted into the NPC matrix, which also catalyzed the formation of graphitized CNTs. When the carbonization temperature was $700{ }^{\circ} \mathrm{C}$, the metal-doped NPC/CNTs achieved a minimum RL of $-32.0 \mathrm{~dB}$. The introduction of nanoparticles could give better dispersion and isolation of the MOF metal center, thus leading to more evenly dispersed ZnCo nanoparticles. Besides, the additive content of the nanoparticles could tune the impedance matching to improve the MA ability.

As discussed above, MOF-based PC composite absorbers have the superiorities of adjustable components, ordered pore structures, excellent repeatability, and strong absorption. However, the relatively heavy nanoparticle composites usually resulted in higher filler loading. In addition, the fabrication process of MOFs usually requires the use of toxic solvents and harsh fabrication conditions. Thus, developing a simple and efficient process for MOF-based PC composite absorber industrial production to reduce the energy and toxic substances in the synthetic route is necessary. On the other hand, in order to maintain a regular pore structure while reducing toxic substances, foam/aerogel-based PC composite absorbers have been extensively studied.

3.2.3 Foam/aerogel-based PC composite absorbers. Recently, carbon foams (CFs) or carbon aerogels with open-hole network structures have attracted great attention as potential microwave absorbers due to their advantages such as low density, outstanding electrical transport property, high surface area and excellent mechanical stability. ${ }^{60,61,118-124}$ Unfortunately, pure PC-based foams/aerogels are seriously limited by their strong conductivities, resulting in poor impedance matching. It is vital to integrate them with other materials to tune the electromagnetic parameters and impedance matching. Generally, there are two ways to construct PC-based composite foams/aerogels. One effective method is to post-process the prepared foams/aerogels, while another one is to introduce modified materials during the process of preparing foams/aerogels before pyrolysis.

The post-treatment method is commonly used for fabricating PC absorbers from melamine foams (MF) due to their high porosities and interconnected conductive network structures 

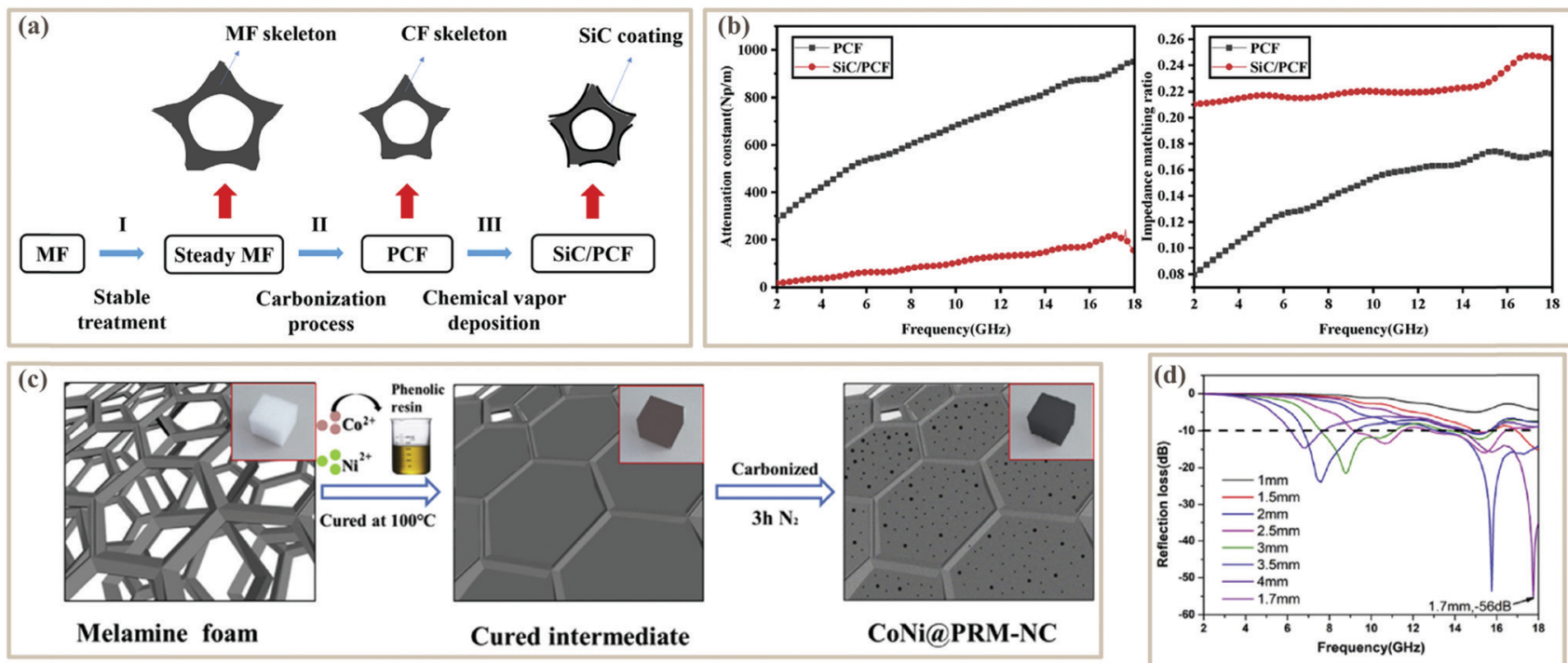

Fig. 5 (a) Three-step preparation process of the SiC/PCF composite. ${ }^{61}$ (b) Impedance matching ratio and attenuation constant of PCF and SiC/PCF. ${ }^{61}$ Reproduced with permission from ref. 61, Copyright (C) 2019, Elsevier. (c) Schematic illustration of CoNiaPRM-NC. ${ }^{120}$ (d) Reflection loss curves of CoNi@PRM-NC. ${ }^{120}$ Reproduced with permission from ref. 120, Copyright (C) 2019, Elsevier.

after pyrolysis. ${ }^{61,119,124}$ The post-treatment method can be further divided into two types. One is to obtain a PC foam by pyrolysis of the foam precursor, and then modify the PC foam. ${ }^{125}$ Ye et al. first got a porous carbon foam (PCF) from a commercial $\mathrm{MF}$, and then deposited an SiC film on its surface through chemical vapor deposition technology ${ }^{61}$ (Fig. 5a). SiC could effectively decrease $\varepsilon^{\prime}$ and $\varepsilon^{\prime \prime}$ of the PCF, which greatly improved the impedance matching ratio $\left(Z_{\mathrm{r}}=Z / Z_{0}=\left(\mu_{\mathrm{r}} / \varepsilon_{\mathrm{r}}\right)^{1 / 2}\right)$ (Fig. 5b). The minimum RL of the PCF/SiC composite reached $-25.93 \mathrm{~dB}$ when the thickness was only $1.05 \mathrm{~mm}$. The other post-treatment method is to decorate the foam skeleton with functional compounds and then pyrolyze them. For example, 3D CoNi alloy particles embedded in an N-doped porous carbon (CoNi@PRM-NC) foam were prepared by using a MF as a sacrificial scaffold and supporting template by Yan et al. ${ }^{120}$ The MF was first coated with $\mathrm{Co}^{2+} / \mathrm{Ni}^{2+}$ and phenolic resol, and then was carbonized at high temperatures (700-1000 ${ }^{\circ} \mathrm{C}$ ) (Fig. 5c). Finally, the 3D CoNi@PRM-NC foam displayed a strong RL of $-56 \mathrm{~dB}$ at $17.8 \mathrm{GHz}$ when the thickness was $1.7 \mathrm{~mm}$ (Fig. 5d). The outstanding MA performance was attributed to the multiple scatterings induced by the conductive foam structures and large attenuation as well as the balance of impedance matching between the dielectric loss and magnetic loss.

Directly integrating other materials into one foam or aerogel during their fabrication process is also an important way to improve the MA performance of pure PC-based foam/aerogel absorbers. ${ }^{60,118,121-123}$ Zhao et al. fabricated $\mathrm{Ni}^{2+}$ /alginate foams as precursors and then pyrolyzed them to get lightweight porous $\mathrm{Ni} /$ carbon foams $\left(\sim 0.1 \mathrm{~g} \mathrm{~cm}^{-3}\right)^{123}$ (Fig. 6a). In the pyrolysis process, alginates underwent thermal decomposition to form graphite carbons, while Ni nanoparticles were reduced simultaneously. Consequently, Ni nanoparticles were uniformly dispersed in the foam without aggregation due to the coordinationcovalent bonds between $\mathrm{Ni}^{2+}$ and alginate. The resultant foam also showed a high BET surface area of $451 \mathrm{~m}^{2} \mathrm{~g}^{-1}$ and a moderate conductivity $\left(6 \mathrm{~S} \mathrm{~m}^{-1}\right)$. Benefiting from these features, the minimum $\mathrm{RL}$ of the $\mathrm{Ni} /$ carbon foam reached $-45 \mathrm{~dB}$ with an effective absorption bandwidth of $-4.5 \mathrm{GHz}$ at a thickness of $2 \mathrm{~mm}$ when the filler loading was only $10 \mathrm{wt} \%$. The conductive carbon network, nano-porosity and uniform $\mathrm{Ni}$ nanoparticles contributed to the great microwave absorption. Similarly, Cheng et al. used cotton fibers as 3D scaffolds, and then sequentially coated with $\mathrm{Co}^{2+}$ and dicyandiamide (DCDA). ${ }^{121}$ After thermal pyrolysis, the metal Co generated as a catalyst could promote the growth of CNTs on the carbon fiber (Fig. 6b). The resultant composite aerogel was elastic and could return to its original shape after compression (Fig. 6b), due to the unique 3D aerogel framework built from the "1D-1D" structure. An RL of $-42 \mathrm{~dB}$ and a broad effective absorption band of $5.08 \mathrm{GHz}$ were achieved at the same matching thickness of $1.6 \mathrm{~mm}$. The outstanding MA performance could be explained in Fig. 6c. Firstly, the conductive carbon fiber network made it possible for electrons to move; in addition, the migrating and hopping of electrons in CNTs would consume EM energy; besides, dipolar polarization would be generated due to the defects of CNTs while interface polarization occurred among different interfaces; and, lastly, magnetic loss including natural resonance and exchange resonance caused by metal co could improve the impedance matching. Porous banana leaflike carbon-doped $\mathrm{MoS}_{2}$ aerogels with low densities $\left(\sim 0.12 \mathrm{~g} \mathrm{~cm}^{-3}\right)$ were also manufactured by Cheng et al. via self-assembly and pyrolysis processes. The hybrid aerogel achieved a minimum RL of $-43 \mathrm{~dB}$ at $5.4 \mathrm{GHz}$ with a low filler loading of $30 \mathrm{wt} \%$ (Fig. 6d). ${ }^{89}$ In conclusion, foam/aerogel PC composite absorbers usually can show strong microwave absorption with relatively low filler loading due to their low densities, outstanding conductive network, and uniformly distributed functional components. It is noteworthy that reduced graphene oxide ( $\mathrm{rGO}$ ) has also been designed into aerogels to make use of these advantages. For 

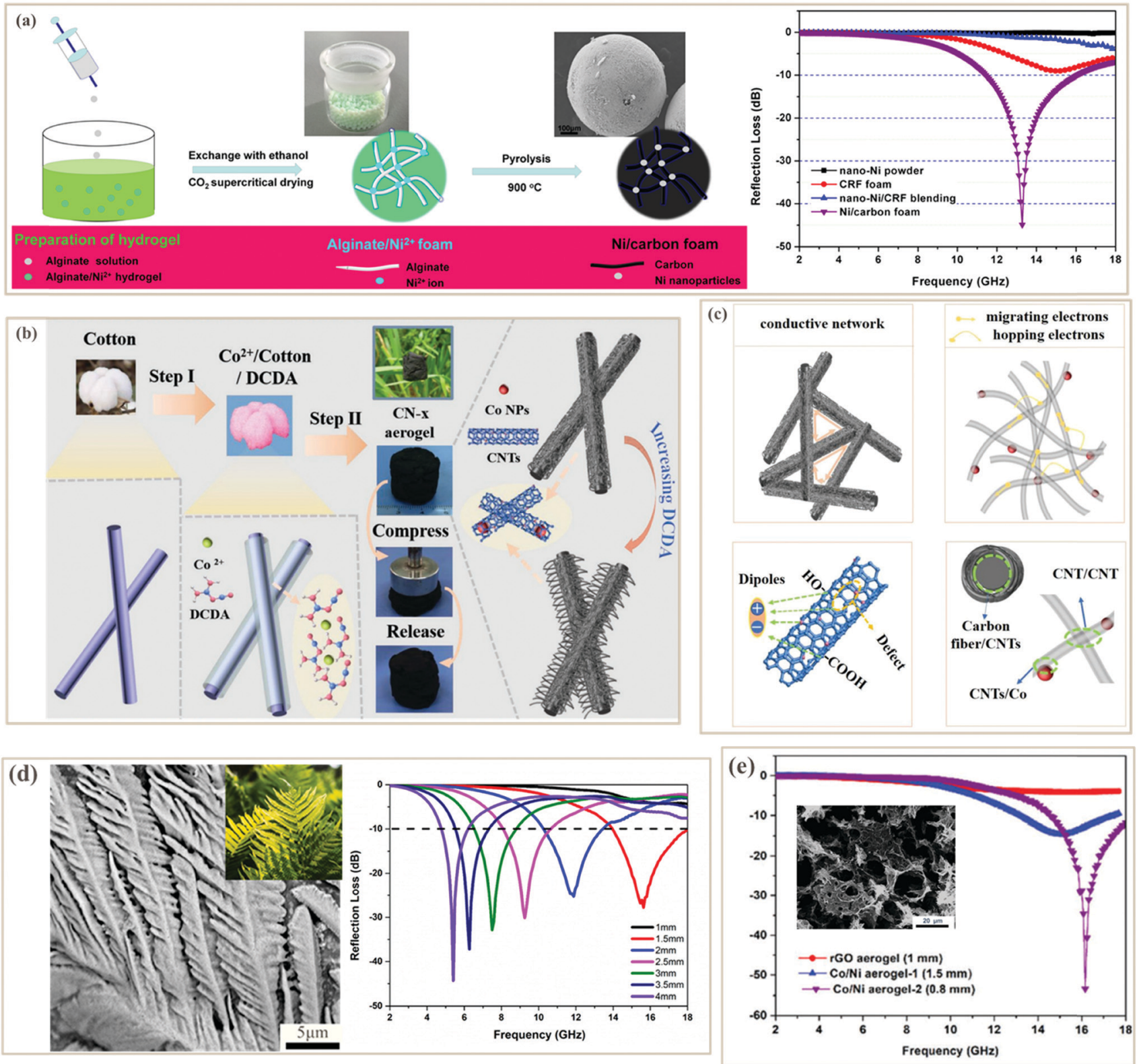

Fig. 6 (a) Schematic illustration, SEM image, and reflection loss curve of the Ni/carbon foam. ${ }^{123}$ Reproduced with permission from ref. 123, Copyright $\mathbb{C}$ 2016. American Chemical Society. (b) Schematic graph of the formation process of CN-x composites. ${ }^{121}$ (c) Schematic description of possible microwave absorption mechanisms of the CN-2.5 aerogel. ${ }^{121}$ Reproduced with permission from ref. 121, Copyright (C) 2019, Wiley. (d) SEM image and reflection loss curves of carbon-doped $\mathrm{MoS}_{2}$ aerogels. ${ }^{89}$ Reproduced with permission from ref. 89, Copyright (C) 2020, American Chemical Society. (e) SEM image and reflection loss curves of CoNi/rGO aerogels. ${ }^{131}$ Reproduced with permission from ref. 131, Copyright (C) 2018, Royal Society of Chemistry.

example, Zhao et al. developed a novel CoNi/rGO aerogel with an ultralow density of $7 \mathrm{mg} \mathrm{cm}^{-3}$ via a facile in situ solvothermal and carbonization process. A minimum RL value of $53.3 \mathrm{~dB}$ was achieved with an ultrathin thickness of $0.8 \mathrm{~mm}$ at a low filler loading of $7 \mathrm{wt} \%$ in the paraffin template, and the effective absorption bandwidth was $>3.5 \mathrm{GHz}$ (Fig. 6e), which provided a potential strategy to prepare excellent microwave absorbers with ultrathin thickness and ultralow density. ${ }^{131}$

3.2.4 Other PC composite absorbers. In addition to using biomass, MOFs, foams, or aerogels as a hard template, directly using porous organic materials as carbon sources is also an acceptable method. ${ }^{82,99,126}$ Cui et al. reported a core-shell porous $\mathrm{Fe}_{2} \mathrm{~N} @ \mathrm{~N}$-doped carbon using dopamine as a carbon source ${ }^{82}$ (Fig. 7a). The resultant porous $\mathrm{Fe}_{2} \mathrm{~N} @ \mathrm{~N}$-doped carbon exhibited a minimum RL of $-59.3 \mathrm{~dB}$ at a thickness of $1.55 \mathrm{~mm}$ (Fig. 7b). However, the filler loading of $50 \mathrm{wt} \%$ was rather high. Cheng et al. fabricated porous CoNi@N-doped carbon nanotube clusters via a facile coordination and carbonization process using melamine as a carbon source. The clusters displayed a hierarchical microstructure (including 0D CoNi nanoparticles, 1D N-doped carbon nanotubes, and a 3D porous network), high surface areas (143.5-205.8 $\left.\mathrm{m}^{2} \mathrm{~g}^{-1}\right)$, and excellent thermal 

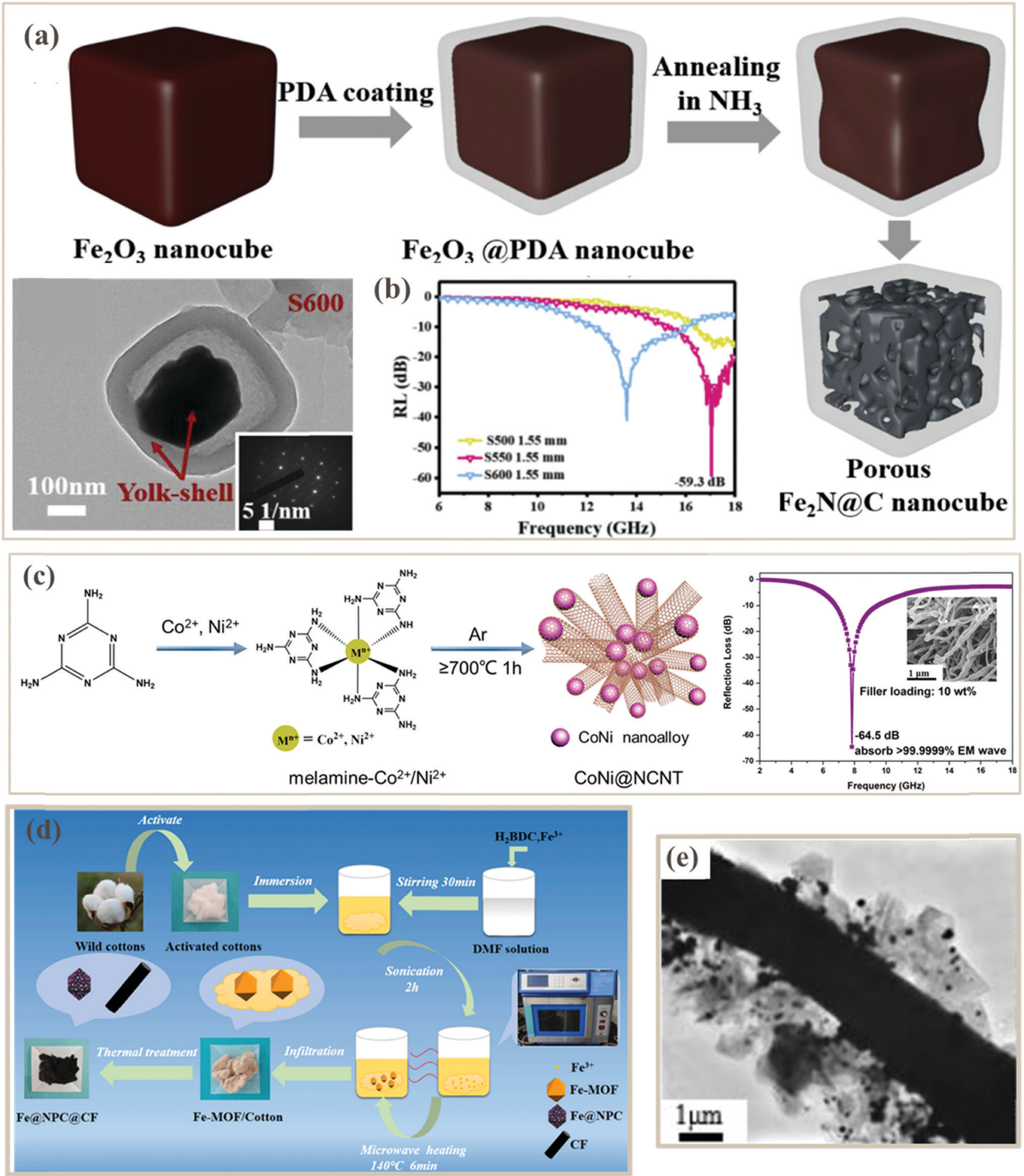

Fig. 7 (a) Schematic illustration of the formation process and TEM image of porous $\mathrm{Fe}_{2} \mathrm{NaN}$-doped $\mathrm{C}$ nanocubes. ${ }^{82}$ (b) $\mathrm{RL}$ curve of Fe ${ }_{2} \mathrm{NaC}$ composites. ${ }^{82}$ Reproduced with permission from ref. 82, Copyright (C) 2019, Elsevier. (c) Schematic illustration of the formation process, SEM image, and RL curve of porous CoNi@N-doped carbon nanotube clusters. ${ }^{132}$ Reproduced with permission from ref. 132, Copyright (C) 2020, Royal Society of Chemistry. (d) Formation process of Fe@NPC@CF composites. ${ }^{115}$ (e) TEM image of an Fe@NPC (aCF composite (S550). ${ }^{115}$ Reproduced with permission from ref. 115, Copyright (C) 2019, Elsevier.

oxidation stabilities $\left(\geq 350^{\circ} \mathrm{C}\right)$. Benefiting from these features, value up to $-64.5 \mathrm{~dB}$ (absorbing $99.9999 \%$ microwaves) at a low the clusters exhibited ultra-strong MA with a minimum RL filler loading of $10 \mathrm{wt} \%$ (Fig. $7 \mathrm{c}$ ). ${ }^{132}$ 
Table 2 Microwave absorption performances of PC-based composite absorbers in recent literature

\begin{tabular}{|c|c|c|c|c|c|c|}
\hline \multirow[b]{2}{*}{ Sample } & \multicolumn{2}{|c|}{ Minimum RL value } & \multirow[b]{2}{*}{ Loading content (wt\%) } & \multicolumn{2}{|c|}{ Effective absorption bandwidth } & \multirow[b]{2}{*}{ Ref. } \\
\hline & $d(\mathrm{~mm})$ & $\mathrm{RL}_{\min }(\mathrm{dB})$ & & $d(\mathrm{~mm})$ & $f(\mathrm{GHz})$ & \\
\hline $\mathrm{RHPC} / \mathrm{Fe}$ & 1.4 & -21.8 & 25 & 1.4 & 5.6 & 77 \\
\hline RHPC/Co & 1.8 & -40.1 & 25 & 1.8 & 2.7 & 77 \\
\hline $\mathrm{Fe}_{3} \mathrm{O}_{4} / \mathrm{PJBC}$ & 4 & -39.5 & 50 & 1.6 & 6.4 & 73 \\
\hline $\mathrm{SiC} / \mathrm{PCF}$ & 1.05 & -25.93 & - & 1.15 & 3.24 & 119 \\
\hline CoNi@PRM-NC & 1.7 & -56 & 35 & 2 & 4.78 & 120 \\
\hline $\mathrm{CN}-2.5$ & 4.5 & -53 & - & 1.6 & 5.08 & 121 \\
\hline $\mathrm{Ni} / \mathrm{C}$ foam & 2 & -45 & 10 & 1.5 & 4.5 & 123 \\
\hline NCM & 2.5 & -50.57 & 15 & 2.5 & 7.44 & 118 \\
\hline CuO@NPC & 1.55 & -57.5 & 50 & 1.55 & 4.7 & 109 \\
\hline FeCo@C-PCF & 1.85 & -56 & 30 & 2.5 & 8.3 & 93 \\
\hline Fe@NPC@CF & 2.5 & -46.2 & 25 & 2.5 & 5.2 & 115 \\
\hline BDC/MnO NR & 1.65 & -58.5 & 30 & 1.42 & 4.5 & 94 \\
\hline Porous $\mathrm{C} / \mathrm{Fe}_{3} \mathrm{C}$ & 2.5 & -57.1 & 50 & 2.5 & 8.16 & 99 \\
\hline $\mathrm{Fe}_{2} \mathrm{~N} @ \mathrm{C}$ & 1.9 & -59.3 & 50 & 1.9 & 4.32 & 82 \\
\hline
\end{tabular}

Besides, combining different templates can also be used to fabricate PC composites. ${ }^{125} \mathrm{Li}$ et al. designed an Fe@nanoporous carbon@carbon fiber (Fe@NPC@CF) composite from MOF and biomass cotton double templates (Fig. 7d), where Fe@NPC was evenly dispersed on the carbon fiber ${ }^{115}$ (Fig. 7e). The porous structure of the composite not only facilitated multiple reflections and scatterings of the incident microwaves but also increased the dipole strength, which further strengthened the interface polarization. Liang et al. designed a ZnO@nanoporous carbon/3D porous carbon network (3DPCN) using a MOF and organic glucose as a carbon source, where the 3DPCN structure acted as the electronic pathway and the nucleation locus for ZIF-8 particles. ${ }^{127}$ Besides, a melamine foam compound with MOF double templates has also been designed by Gu et al. as a multifunctional microwave absorber. Remarkably, the resultant carbon-based foam presented strong microwave absorbing properties with an effective microwave bandwidth of $5.64 \mathrm{GHz}$ at a thin layer of $2.1 \mathrm{~mm}$. The high porosity, threedimensional structure and combined effects of multiple components of the hybrid foam contributed to a superior heat insulating feature and thermal stealth character. ${ }^{128}$ Despite many benefits, the complex preparation process still seriously limited their applications.

Especially, it should be noted that some interesting technologies such as arc-discharge plasma technology, electrospinning technology, and microwave-assisted methods are also utilized for fabricating PC, which provides a new strategy for the development of microwave absorbers. ${ }^{126,129,130}$ For example, Li et al. synthetized a tremella-like porous $\mathrm{NiCo} / \mathrm{C}$ composite through a microwave-assisted method, and the fabrication time was greatly decreased. ${ }^{126}$

Table 2 summarizes the MA properties of recent PC-based composite absorbers. Accordingly, PC-based composites have been widely used in MA, and some of them could meet the demand of "thin thickness, light weight, wide frequency bandwidth, and strong absorption". However, many studies paid attention to designing new nanostructures to obtain satisfactory MA performance, and the relevant absorption mechanism remains to be studied. Also, current absorbing materials mainly focus on the absorption of EM waves in the band of 2-18 GHz. Whereas, with the development of meter-wave and millimeterwave detection technology, higher requirements are put forward for multi-band absorption of absorbing materials.

\section{Conclusions and perspectives}

Based on the above discussion, it can be concluded that PC-based absorbers are potential microwave absorption materials due to their facial synthesis strategies, low densities, strong attenuation abilities, adjustable EM parameters, simple modification methods, and abundant raw materials. In this review, we discussed the influence of porous carbon materials on MA performances. That is, the porous structure will contribute to light weight and better impedance matching while the complex permittivity can be tuned via the graphitization of carbon. Then we systematically summarized the latest research progress on PC-based absorbers, according to the precursor types, and put forward promising approaches for improving the MA performance of PC-based materials. For pure PC absorbers, the direct pyrolysis method is the simplest, while the activation method would further increase the pore volumes and the template method could better control the pore size. But pure PC absorbers are sometimes limited by weak impedance matching due to their high conductivity and strong dielectric loss. To solve this problem, regulating the relationship between the microstructure and carbon composition can effectively improve the impedance matching, thereby ensuring application prospects in MA. Besides, hybridization with other functional materials can introduce more interface polarization loss and magnetic loss, which would also tune the impedance matching and improve the MA performance of PC absorbers. For PC-based composites, on one hand, the precursors are abundant, including polymer foams, aerogels, MOFs, biomass, and organic materials. On the other hand, various modification methods are effective strategies in tailoring the microstructures and introducing different compositions. In summary, controlling the pyrolysis temperature, tuning the composition and designing the microstructure are the important factors to achieve excellent MA performance of PC-based materials. 
As shown in Tables 1 and 2, PC-based materials have made prominent achievements in MA. Even so, it should be emphasized that current research is still restricted by many aspects. Firstly, it has been proved that the porous structure would improve the impedance matching and enhance the MA properties of PC-based materials. However, the influences of the pore size and pore distribution on microwave absorption are still unclear. Secondly, plenty of achievements have been made regarding PC-based composite absorbers. Nevertheless, many studies paid attention to designing new nanostructures to obtain satisfactory MA properties, and it remains essential to study the relevant absorption mechanism. For example, it has been widely recognized that conductivity loss and polarization (CaP) are two of the dominant factors in determining the complex permittivity. However, few studies have been reported on the quantitative relationship between CaP and permittivity, as well as the preferred dissipation mechanism in different types of dielectrics (e.g., semiconductors/ graphitized carbon, graphene, and so on). ${ }^{80}$ Thirdly, the construction of high-performance absorbing materials with "low density, thin coating thickness, wide absorption bandwidth and strong absorption" is still a major concern in the field of absorbing materials. But current absorbing materials mainly focus on the absorption of EM waves in the band of 2-18 GHz. Whereas, with the development of meter-wave and millimeterwave detection technology, higher requirements are put forward for multi-band absorption of absorbing materials. Future absorbing materials should cover multi-band absorption including infrared light, microwaves, etc. Finally, considering wide applications, the combination of MA with other functions (such as higher temperature resistance, corrosion resistance, superhydrophobicity, etc.) is also an important direction for the future development of PC-based absorbers. Ideal absorbing materials should adapt to different harsh environments. The development of multifunctional and multiband absorbing materials will be a future research trend.

\section{Conflicts of interest}

There are no conflicts to declare.

\section{Acknowledgements}

This work was supported by the Sichuan Science and Technology Program (2019YJ014), Fundamental Research Funds for the Central Universities, and Young Elite Scientists Sponsorship Program by CAST.

\section{References}

1 B. Quan, X. Liang, G. Ji, Y. Cheng, W. Liu, J. Ma, Y. Zhang, D. Li and G. Xu, J. Alloys Compd., 2017, 728, 1065-1075.

2 L. Huang, C. Chen, Z. Li, Y. Zhang, H. Zhang, J. Lu, S. Ruan and Y. J. Zeng, Nanotechnology, 2020, 31, 162001.

3 G. He, Y. Duan and H. Pang, Nano-Micro Lett., 2020, 12, 57. 4 B. Deng, Z. Xiang, J. Xiong, Z. Liu, L. Yu and W. Lu, NanoMicro Lett., 2020, 12, 55.
5 Z. Xiang, J. Xiong, B. Deng, E. Cui, L. Yu, Q. Zeng, K. Pei, R. Che and W. Lu, J. Mater. Chem. C, 2020, 8, 2123-2134.

6 X. Wang, Y. Lu, T. Zhu, S. Chang and W. Wang, Chem. Eng. J., 2020, 388, 124317.

7 X. Shi, Z. Liu, W. You, X. Zhao and R. Che, J. Mater. Chem. C, 2018, 6, 7790-7796.

8 Y. Jiang, X. Xie, Y. Chen, Y. Liu, R. Yang and G. Sui, J. Mater. Chem. C, 2018, 6, 8679-8687.

9 Y. Duan, Z. Xiao, X. Yan, Z. Gao, Y. Tang, L. Hou, Q. Li, G. Ning and Y. Li, ACS Appl. Mater. Interfaces, 2018, 10, 40078-40087.

10 J.-C. Shu, X.-Y. Yang, X.-R. Zhang, X.-Y. Huang, M.-S. Cao, L. Li, H.-J. Yang and W.-Q. Cao, Carbon, 2020, 162, 157-171.

11 F. Meng, H. Wang, F. Huang, Y. Guo, Z. Wang, D. Hui and Z. Zhou, Composites, Part B, 2018, 137, 260-277.

12 X. Liang, W. Liu, Y. Cheng, J. Lv, S. Dai, D. Tang, B. Zhang and G. Ji, J. Alloys Compd., 2018, 749, 887-899.

13 H. Zhao, Y. Cheng, W. Liu, L. Yang, B. Zhang, L. P. Wang, G. Ji and Z. J. Xu, Nano-Micro Lett., 2019, 11, 24.

14 N. Li, G. W. Huang, Y. Q. Li, H. M. Xiao, Q. P. Feng, N. Hu and S. Y. Fu, ACS Appl. Mater. Interfaces, 2017, 9, 2973-2983.

15 S. K. Singh, M. J. Akhtar and K. K. Kar, ACS Appl. Mater. Interfaces, 2018, 10, 24816-24828.

16 L. Wang, X. Li, Q. Li, Y. Zhao and R. Che, ACS Appl. Mater. Interfaces, 2018, 10, 22602-22610.

17 Y. Wang, X. Gao, X. Wu, W. Zhang, C. Luo and P. Liu, Chem. Eng. J., 2019, 375, 121942.

18 Y. Wang, X. Di, X. Gao, X. Wu and P. Wang, J. Alloys Compd., 2020, 843, 156031.

19 Y. Wang, X. Di, X. Wu and X. Li, J. Alloys Compd., 2020, 846, 156215.

20 Y. Wang, X. Gao, Y. Fu, X. Wu, Q. Wang, W. Zhang and C. Luo, Composites, Part B, 2019, 169, 221-228.

21 A. Chaudhary, S. Kumari, R. Kumar, S. Teotia, B. P. Singh, A. P. Singh, S. K. Dhawan and S. R. Dhakate, ACS Appl. Mater. Interfaces, 2016, 8, 10600-10608.

22 M.-M. Lu, W.-Q. Cao, H.-L. Shi, X.-Y. Fang, J. Yang, Z.-L. Hou, H.-B. Jin, W.-Z. Wang, J. Yuan and M.-S. Cao, J. Mater. Chem. A, 2014, 2, 10540.

23 F. Wen, F. Zhang and Z. Liu, J. Phys. Chem. C, 2011, 115, 14025-14030.

24 M.-S. Cao, W.-L. Song, Z.-L. Hou, B. Wen and J. Yuan, Carbon, 2010, 48, 788-796.

25 W.-l. Song, M.-s. Cao, Z.-l. Hou, J. Yuan and X.-y. Fang, Scr. Mater., 2009, 61, 201-204.

26 Y. Liu, Z. Chen, Y. Zhang, R. Feng, X. Chen, C. Xiong and L. Dong, ACS Appl. Mater. Interfaces, 2018, 10, 13860-13868.

27 Y. Jiang, Y. Chen, Y.-J. Liu and G.-X. Sui, Chem. Eng. J., 2018, 337, 522-531.

28 Y. Zheng, X. Wang, S. Wei, B. Zhang, M. Yu, W. Zhao and J. Liu, Composites, Part A, 2017, 95, 237-247.

29 W. Feng, Y. Wang, J. Chen, L. Wang, L. Guo, J. Ouyang, D. Jia and Y. Zhou, Carbon, 2016, 108, 52-60.

30 Y. Zhang, Y. Huang, T. Zhang, H. Chang, P. Xiao, H. Chen, Z. Huang and Y. Chen, Adv. Mater., 2015, 27, 2049-2053.

31 M. Zhang, X. Fang, Y. Zhang, J. Guo, C. Gong, D. Estevez, F. Qin and J. Zhang, Nanotechnology, 2020, 31, 275707. 
32 X. Xu, F. Ran, Z. Fan, Z. Cheng, T. Lv, L. Shao and Y. Liu, ACS Appl. Mater. Interfaces, 2020, 12, 17870-17880.

33 S. Xiao, C. Zhou, X. Ye, Z. Lian, N. Zhang, J. Yang, W. Chen and H. Li, ACS Appl. Mater. Interfaces, 2020, 12, 32604-32614.

34 C. Wu, Z. Chen, M. Wang, X. Cao, Y. Zhang, P. Song, T. Zhang, X. Ye, Y. Yang, W. Gu, J. Zhou and Y. Huang, Small, 2020, 16, 2001686.

35 M. Ma, W. Li, Z. Tong, Y. Yang, Y. Ma, Z. Cui, R. Wang, P. Lyu and W. Huang, Mater. Des., 2020, 188, 108462.

$36 \mathrm{~J} . \mathrm{Hu}, \mathrm{Y}$. Shen, L. Xu and Y. Liu, Chem. Phys. Lett., 2020, 739, 136953.

37 H. Duan, H. Zhu, J. Gao, D.-X. Yan, K. Dai, Y. Yang, G. Zhao, Y. Liu and Z.-M. Li, J. Mater. Chem. A, 2020, 8, 9146-9159.

38 S. Dong, X. Zhang, X. Li, J. Chen, P. Hu and J. Han, Chem. Eng. J., 2020, 392, 123817.

39 Y. Chen, P. Potschke, J. Pionteck, B. Voit and H. Qi, ACS Appl. Mater. Interfaces, 2020, 12, 22088-22098.

40 Z. Zhang, Q. Lv, Y. Chen, H. Yu, H. Liu, G. Cui, X. Sun and L. Li, Nanomaterials, 2019, 9, 833.

41 D. Zhang, T. Liu, J. Cheng, Q. Cao, G. Zheng, S. Liang, H. Wang and M.-S. Cao, Nano-Micro Lett., 2019, 11, 38.

42 H. Wang and H. Ma, Nanotechnology, 2019, 31, 095711.

43 J. Ma, J. Shu, W. Cao, M. Zhang, X. Wang, J. Yuan and M. Cao, Composites, Part B, 2019, 166, 187-195.

44 J. Luo, Y. Hu, L. Xiao, G. Zhang, H. Guo, G. Hao and W. Jiang, Nanotechnology, 2019, 31, 085708.

45 J. Ma, X. Wang, W. Cao, C. Han, H. Yang, J. Yuan and M. Cao, Chem. Eng. J., 2018, 339, 487-498.

46 J. Li, Y. Xie, W. Lu and T.-W. Chou, Carbon, 2018, 129, 76-84.

47 P. Zhou, J. Wan, X. Wang, K. Xu, Y. Gong and L. Chen, J. Colloid Interface Sci., 2020, 575, 96-107.

48 H. Y. Zhou, Z. Y. Sui, F. L. Zhao, Y. N. Sun, H. Y. Wang and B. H. Han, Nanotechnology, 2020, 31, 315601.

49 W. Zhao, Y. Shen, H. Zhang, Y. Wang, Y. Wu, H. Wu, M. Zou, Q. Wang, Y. Li and A. Cao, ACS Appl. Mater. Interfaces, 2020, 12, 27045-27054.

50 L. Tong, L. L. Zhang, Y. C. Wang, L. Y. Wan, Q. Q. Yan, C. Hua, C. J. Jiao, Z. Y. Zhou, Y. W. Ding, B. Liu and H. W. Liang, ACS Appl. Mater. Interfaces, 2020, 12, 25211-25220.

51 J. Li, K. Han, D. Wang, Z. Teng, Y. Cao, J. Qi, M. Li and M. Wang, Carbon, 2020, 164, 42-50.

52 G.-Y. Hou, Z.-Y. Lyu, Y.-P. Tang, H.-Z. Cao and G.-Q. Zheng, Int. J. Hydrogen Energy, 2020, 45, 16049-16059.

53 N. Guo, W. Luo, R. Guo, D. Qiu, Z. Zhao, L. Wang, D. Jia and J. Guo, J. Alloys Compd., 2020, 834, 155115.

54 Y. Zhai, J. Wang, Q. Gao, Y. Fan, C. Hou, Y. Hou, H. Liu, Q. Shao, S. Wu, L. Zhao, T. Ding, F. Dang and Z. Guo, J. Catal., 2019, 377, 534-542.

55 L. Miao, X. Qian, D. Zhu, T. Chen, G. Ping, Y. Lv, W. Xiong, Y. Liu, L. Gan and M. Liu, Chin. Chem. Lett., 2019, 30, 1445-1449.

56 M. Culebras, H. Geaney, A. Beaucamp, P. Upadhyaya, E. Dalton, K. M. Ryan and M. N. Collins, ChemSusChem, 2019, 12, 4516-4521.

57 Y. Cheng, J. Cao, Y. Li, Z. Li, H. Zhao, G. Ji and Y. Du, ACS Sustainable Chem. Eng., 2017, 6, 1427-1435.
58 C. Liang and Z. Wang, Chem. Eng. J., 2019, 373, 598-605.

59 R. Wang, M. He, Y. Zhou, S. Nie, Y. Wang, W. Liu, Q. He, W. Wu, X. Bu and X. Yang, Carbon, 2020, 156, 378-388.

60 H.-B. Zhao, J.-B. Cheng and Y.-Z. Wang, J. Alloys Compd., 2018, 736, 71-79.

61 X. Ye, Z. Chen, S. Ai, B. Hou, J. Zhang, X. Liang, Q. Zhou, H. Liu and S. Cui, J. Alloys Compd., 2019, 791, 883-891.

62 Y. Cheng, H. Zhao, Y. Zhao, J. Cao, J. Zheng and G. Ji, Carbon, 2020, 161, 870-879.

63 H. Xu, X. Yin, M. Zhu, M. Han, Z. Hou, X. Li, L. Zhang and L. Cheng, ACS Appl. Mater. Interfaces, 2017, 9, 6332-6341.

64 Y. Huang, Y. Wang, Z. Li, Z. Yang, C. Shen and C. He, J. Phys. Chem. C, 2014, 118, 26027-26032.

65 D. Li, H. Liao, H. Kikuchi and T. Liu, ACS Appl. Mater. Interfaces, 2017, 9, 44704-44714.

66 Z. Wu, K. Tian, T. Huang, W. Hu, F. Xie, J. Wang, M. Su and L. Li, ACS Appl. Mater. Interfaces, 2018, 10, 11108-11115.

67 L. Wang, P. Zhou, Y. Guo, J. Zhang, X. Qiu, Y. Guan, M. Yu, H. Zhu and Q. Zhang, RSC Adv., 2019, 9, 9718-9728.

68 W.-L. Song, M.-S. Cao, L.-Z. Fan, M.-M. Lu, Y. Li, C.-Y. Wang and H.-F. Ju, Carbon, 2014, 77, 130-142.

69 J. Chen, X. Liang, W. Liu, W. Gu, B. Zhang and G. Ji, Dalton Trans., 2019, 48, 10145-10150.

70 Y. Cheng, Z. Li, Y. Li, S. Dai, G. Ji, H. Zhao, J. Cao and Y. Du, Carbon, 2018, 127, 643-652.

71 X. Zhou, Z. Jia, A. Feng, X. Wang, J. Liu, M. Zhang, H. Cao and G. Wu, Carbon, 2019, 152, 827-836.

72 Z. Zhang, H. Zhao, W. Gu, L. Yang and B. Zhang, Sci. Rep., 2019, 9, 18617.

73 L. Wang, H. Guan, J. Hu, Q. Huang, C. Dong, W. Qian and Y. Wang, J. Alloys Compd., 2019, 803, 1119-1126.

74 Y. Jiang, X. Fu, Z. Zhang, G. Fan, Y. Liu, W. Du, X. Wang, C. Cheng and R. Fan, J. Mater. Sci.: Mater. Electron., 2019, 30, 19173-19181.

75 Y. Wei, H. Liu, S. Liu, M. Zhang, Y. Shi, J. Zhang, L. Zhang and C. Gong, Compos. Commun., 2018, 9, 70-75.

76 J. Xi, E. Zhou, Y. Liu, W. Gao, J. Ying, Z. Chen and C. Gao, Carbon, 2017, 124, 492-498.

77 J. Fang, Y. Shang, Z. Chen, W. Wei, Y. Hu, X. Yue and Z. Jiang, J. Mater. Chem. C, 2017, 5, 4695-4705.

78 X. Qiu, L. Wang, H. Zhu, Y. Guan and Q. Zhang, Nanoscale, 2017, 9, 7408-7418.

79 M. S. Cao, X. X. Wang, M. Zhang, J. C. Shu, W. Q. Cao, H. J. Yang, X. Y. Fang and J. Yuan, Adv. Funct. Mater., 2019, 29, 1807398.

80 B. Quan, W. Shi, S. J. H. Ong, X. Lu, P. L. Wang, G. Ji, Y. Guo, L. Zheng and Z. J. Xu, Adv. Funct. Mater., 2019, 29, 1901236.

81 X. Zhang, J. Qiao, J. Zhao, D. Xu, F. Wang, C. Liu, Y. Jiang, L. Wu, P. Cui, L. Lv, Q. Wang, W. Liu, Z. Wang and J. Liu, ACS Appl. Mater. Interfaces, 2019, 11, 35959-35968.

82 X. Cui, X. Liang, J. Chen, W. Gu, G. Ji and Y. Du, Carbon, 2020, 156, 49-57.

83 X. Cui, X. Liang, W. Liu, W. Gu, G. Ji and Y. Du, Chem. Eng. J., 2020, 381, 122589.

84 A. Bhatnagar, W. Hogland, M. Marques and M. Sillanpää, Chem. Eng. J., 2013, 219, 499-511. 
85 D. Liu, R. Qiang, Y. Du, Y. Wang, C. Tian and X. Han, J. Colloid Interface Sci., 2018, 514, 10-20.

86 D. Ding, Y. Wang, X. Li, R. Qiang, P. Xu, W. Chu, X. Han and Y. Du, Carbon, 2017, 111, 722-732.

87 Y. Wang, Y. Du, R. Qiang, C. Tian, P. Xu and X. Han, Adv. Mater. Interfaces, 2016, 3, 1500684.

88 R. Qiang, Y. Du, Y. Wang, N. Wang, C. Tian, J. Ma, P. Xu and X. Han, Carbon, 2016, 98, 599-606.

89 J. B. Cheng, H. B. Zhao, M. Cao, M. E. Li, A. N. Zhang, S. L. Li and Y. Z. Wang, ACS Appl. Mater. Interfaces, 2020, 12, 26301-26312.

90 T. Zhang, D. Zhao, L. Wang, R. Meng, H. Zhao, P. Zhou, L. Xia, B. Zhong, H. Wang and G. Wen, J. Alloys Compd., 2020, 819, 153269.

91 P. Zhou, X. Wang, L. Wang, J. Zhang, Z. Song, X. Qiu, M. Yu and Q. Zhang, J. Alloys Compd., 2019, 805, 1071-1080.

92 H. Wang, Y. Zhang, Q. Wang, C. Jia, P. Cai, G. Chen, C. Dong and H. Guan, RSC Adv., 2019, 9, 9126-9135.

93 Z. Song, X. Liu, X. Sun, Y. Li, X. Nie, W. Tang, R. Yu and J. Shui, Carbon, 2019, 151, 36-45.

94 P. Hu, S. Dong, X. Li, J. Chen, X. Zhang, P. Hu and S. Zhang, J. Mater. Chem. C, 2019, 7, 9219-9228.

95 H. Guan, H. Wang, Y. Zhang, C. Dong, G. Chen, Y. Wang and J. Xie, Appl. Surf. Sci., 2018, 447, 261-268.

96 X. Zhang, J. Xu, X. Liu, S. Zhang, H. Yuan, C. Zhu, X. Zhang and Y. Chen, Carbon, 2019, 155, 233-242.

97 L. Wang, Y. Guan, X. Qiu, H. Zhu, S. Pan, M. Yu and Q. Zhang, Chem. Eng. J., 2017, 326, 945-955.

98 Y. Cheng, J. Z. Y. Seow, H. Zhao, Z. J. Xu and G. Ji, NanoMicro Lett., 2020, 12, 102.

99 T. Huang, Z. Wu, Q. Yu, D. Tan and L. Li, Chem. Eng. J., 2019, 359, 69-78.

100 X. Liang, Z. Man, B. Quan, J. Zheng, W. Gu, Z. Zhang and G. Ji, Nano-Micro Lett., 2020, 12, 125.

101 Z. Zhang, Y. Lv, X. Chen, Z. Wu, Y. He, L. Zhang and Y. Zou, J. Magn. Magn. Mater., 2019, 487, 165334.

102 X. Xu, F. Ran, H. Lai, Z. Cheng, T. Lv, L. Shao and Y. Liu, ACS Appl. Mater. Interfaces, 2019, 11, 35999-36009.

103 J. Ouyang, Z. He, Y. Zhang, H. Yang and Q. Zhao, ACS Appl. Mater. Interfaces, 2019, 11, 39304-39314.

104 W. Liu, L. Liu, Z. Yang, J. Xu, Y. Hou and G. Ji, ACS Appl. Mater. Interfaces, 2018, 10, 8965-8975.

105 W. Liu, Q. Shao, G. Ji, X. Liang, Y. Cheng, B. Quan and Y. Du, Chem. Eng. J., 2017, 313, 734-744.

106 W. Liu, L. Liu, G. Ji, D. Li, Y. Zhang, J. Ma and Y. Du, ACS Sustainable Chem. Eng., 2017, 5, 7961-7971.

107 Y. Yin, X. Liu, X. Wei, R. Yu and J. Shui, ACS Appl. Mater. Interfaces, 2016, 8, 34686-34698.

108 R. Qiang, Y. Du, D. Chen, W. Ma, Y. Wang, P. Xu, J. Ma, H. Zhao and X. Han, J. Alloys Compd., 2016, 681, 384-393.
109 J. Ma, X. Zhang, W. Liu and G. Ji, J. Mater. Chem. C, 2016, 4, 11419-11426.

110 X. Zhang, G. Ji, W. Liu, B. Quan, X. Liang, C. Shang, Y. Cheng and Y. Du, Nanoscale, 2015, 7, 12932-12942.

111 Q. Wu, J. Wang, H. Jin, T. Yan, G. Yi, X. Su, W. Dai and X. Wang, Mater. Lett., 2019, 244, 138-141.

112 X. Liang, B. Quan, Y. Sun, G. Ji, Y. Zhang, J. Ma, D. Li, B. Zhang and Y. Du, Part. Part. Syst. Charact., 2017, 34, 1700006.

113 X. Liang, B. Quan, G. Ji, W. Liu, Y. Cheng, B. Zhang and Y. Du, Inorg. Chem. Front., 2016, 3, 1516-1526.

114 L. Wang, X. Yu, X. Li, J. Zhang, M. Wang and R. Che, Chem. Eng. J., 2020, 383, 123099.

115 X. Li, E. Cui, Z. Xiang, L. Yu, J. Xiong, F. Pan and W. Lu, J. Alloys Compd., 2020, 819, 152952.

116 X. Zhang, G. Ji, W. Liu, X. Zhang, Q. Gao, Y. Li and Y. Du, J. Mater. Chem. C, 2016, 4, 1860-1870.

117 W. Liu, S. Tan, Z. Yang and G. Ji, ACS Appl. Mater. Interfaces, 2018, 10, 31610-31622.

118 L. Guo, Q.-D. An, Z.-Y. Xiao, S.-R. Zhai, W.-J. Cai, H.S. Wang and Z.-C. Li, J. Alloys Compd., 2020, 812, 152167.

119 X. Ye, Z. Chen, S. Ai, B. Hou, J. Zhang, X. Liang, Q. Zhou, H. Liu and S. Cui, J. Adv. Ceram., 2019, 8, 479-488.

120 J. Yan, Y. Huang, C. Chen, X. Liu and H. Liu, Carbon, 2019, 152, 545-555.

121 Y. Cheng, H. Zhao, H. Lv, T. Shi, G. Ji and Y. Hou, Adv. Electron. Mater., 2019, 6, 1900796.

122 P. Xie, H. Li, B. He, F. Dang, J. Lin, R. Fan, C. Hou, H. Liu, J. Zhang, Y. Ma and Z. Guo, J. Mater. Chem. C, 2018, 6, 8812-8822.

123 H. B. Zhao, Z. B. Fu, H. B. Chen, M. L. Zhong and C. Y. Wang, ACS Appl. Mater. Interfaces, 2016, 8, 1468-1477.

124 C. Liu, Y. Duan, J. Cai, X. Li, D. Zhang, J. Gao and Y. Che, Mater. Res. Express, 2019, 6, 106114.

125 N. Yang, Z. X. Luo, G. R. Zhu, S. C. Chen, X. L. Wang, G. Wu and Y. Z. Wang, ACS Appl. Mater. Interfaces, 2019, 11, 35987-35998.

126 C. Li, J. Sui, Z. Zhang, X. Jiang, Z. Zhang and L. Yu, Chem. Eng. J., 2019, 375, 122017.

127 X. Liang, B. Quan, Z. Man, B. Cao, N. Li, C. Wang, G. Ji and T. Yu, ACS Appl. Mater. Interfaces, 2019, 11, 30228-30233.

128 W. Gu, J. Tan, J. Chen, Z. Zhang, Y. Zhao, J. Yu and G. Ji, ACS Appl. Mater. Interfaces, 2020, 12, 28727-28737.

129 J. Lv, X. Liang, G. Ji, B. Quan, W. Liu and Y. Du, ACS Sustainable Chem. Eng., 2018, 6, 7239-7249.

130 X. Liang, B. Quan, J. Chen, W. Gu, B. Zhang and G. Ji, ACS Appl. Nano Mater., 2018, 1, 5712-5721.

131 H.-B. Zhao, J.-B. Cheng, J.-Y. Zhu and Y.-Z. Wang, J. Mater. Chem. C, 2019, 7, 441-448.

132 J.-B. Cheng, W.-J. Yuan, A.-N. Zhang, H.-B. Zhao and Y.-Z. Wang, J. Mater. Chem. C, 2020, DOI: 10.1039/d0tc03377d. 